\title{
Cannabinoids and Pain: New Insights From Old Molecules
}

OPEN ACCESS

Edited by:

Francisco Lopez-Munoz, Universidad Camilo José Cela, Spain

Reviewed by:

Donald I. Abrams,

University of California,

San Francisco, United States

Li Zhang,

National Institutes of Health $(\mathrm{N} / \mathrm{H})$,

United States

*Correspondence:

Sonja Vučković

vuckovicsonja1@gmail.com;

sonyav@sbb.rs

Specialty section:

This article was submitted to

Neuropharmacology,

a section of the journal

Frontiers in Pharmacology

Received: 27 July 2018

Accepted: 15 October 2018

Published: 13 November 2018

Citation:

Vučković S, Srebro D, Vujović KS,

Vučetić Č and Prostran M (2018) Cannabinoids and Pain: New Insights

From Old Molecules.

Front. Pharmacol. 9:1259.

doi: 10.3389/fphar.2018.01259

\section{Sonja Vučković1*, Dragana Srebro', Katarina Savić Vujović1, Čedomir Vučetić ${ }^{2,3}$ and Milica Prostran ${ }^{1}$}

\begin{abstract}
1 Department of Pharmacology, Clinical Pharmacology and Toxicology, Faculty of Medicine, University of Belgrade, Belgrade, Serbia, ${ }^{2}$ Clinic of Orthopaedic Surgery and Traumatology, Clinical Center of Serbia, Belgrade, Serbia, ${ }^{3}$ Faculty of Medicine,

University of Belgrade, Belgrade, Serbia
\end{abstract}

Cannabis has been used for medicinal purposes for thousands of years. The prohibition of cannabis in the middle of the 20th century has arrested cannabis research. In recent years there is a growing debate about the use of cannabis for medical purposes. The term 'medical cannabis' refers to physician-recommended use of the cannabis plant and its components, called cannabinoids, to treat disease or improve symptoms. Chronic pain is the most commonly cited reason for using medical cannabis. Cannabinoids act via cannabinoid receptors, but they also affect the activities of many other receptors, ion channels and enzymes. Preclinical studies in animals using both pharmacological and genetic approaches have increased our understanding of the mechanisms of cannabinoid-induced analgesia and provided therapeutical strategies for treating pain in humans. The mechanisms of the analgesic effect of cannabinoids include inhibition of the release of neurotransmitters and neuropeptides from presynaptic nerve endings, modulation of postsynaptic neuron excitability, activation of descending inhibitory pain pathways, and reduction of neural inflammation. Recent meta-analyses of clinical trials that have examined the use of medical cannabis in chronic pain present a moderate amount of evidence that cannabis/cannabinoids exhibit analgesic activity, especially in neuropathic pain. The main limitations of these studies are short treatment duration, small numbers of patients, heterogeneous patient populations, examination of different cannabinoids, different doses, the use of different efficacy endpoints, as well as modest observable effects. Adverse effects in the short-term medical use of cannabis are generally mild to moderate, well tolerated and transient. However, there are scant data regarding the long-term safety of medical cannabis use. Larger well-designed studies of longer duration are mandatory to determine the long-term efficacy and longterm safety of cannabis/cannabinoids and to provide definitive answers to physicians and patients regarding the risk and benefits of its use in the treatment of pain. In conclusion, the evidence from current research supports the use of medical cannabis in the treatment of chronic pain in adults. Careful follow-up and monitoring of patients using cannabis/cannabinoids are mandatory.

Keywords: cannabis/cannabinoids, pain, pharmacodynamics, pharmacokinetics, efficacy, safety, animals, humans 


\section{INTRODUCTION}

Pain is one of the most common symptoms of disease. Acute pain is usually successfully managed with non-steroidal antiinflammatory drugs (NSAIDs) and/or opioids (Vučković S. et al., 2006; Vučković S.M. et al., 2006; Vučković et al., 2009, Vučković et al., 2016), but chronic pain is often difficult to treat and can be very disabling (Gatchel et al., 2014). An adjuvant is a drug that is not primarily intended to be an analgesic but can be used to reduce pain either alone or in combination with other pain medications (Bair and Sanderson, 2011). Some of these drugs have been known for some time, but their acceptance has waxed and waned over time (Vučković et al., 2015; Srebro et al., 2016; Tomić et al., 2018). However, new approaches to targeting the pain pathway have been developed and adjuvant analgesics continue to attract both scientific and medical interest as constituents of a multimodal approach to pain management (Yaksh et al., 2015). The role of cannabis plant and its components, called cannabinoids, as adjuvant analgesics in the treatment of chronic pain, has been the subject of longstanding controversy (NASEM, 2017).

Flowering plants within the genus Cannabis (also known as marijuana) in the family Cannabaceae have been cultivated for thousands of years in many parts of the world for spiritual, recreational and medicinal purposes. Preparations of the cannabis plant, which are taken by smoking or oral ingestion, have been observed to produce analgesic, antianxiety, anti-spasmodic, muscle relaxant, anti-inflammatory and anticonvulsant effects (Andre et al., 2016). However, the prohibition of cannabis cultivation, supply and possession from the middle of the 20th century (due to its psychoactivity and potential for producing dependence), has impeded cannabis research (ElSohly et al., 2017). In recent years there is a growing debate about cannabis use for medical purposes. In many countries cannabis use for medical reasons is legal and some countries have also decriminalized or legalized the recreational use of cannabis.

The term medical cannabis is used to refer to the physicianrecommended use of cannabis and its constituents, cannabinoids, to treat disease or improve symptoms (Rahn and Hohmann, 2009). The use of cannabis and cannabinoids may be limited by its psychotropic side effects (e.g., euphoria, anxiety, paranoia) or other central nervous system (CNS)-related undesired effects (cognitive impairment, depression of motor activity, addiction), which occur because of activation of cannabinoid CB1 receptors in the CNS (Volkow et al., 2014). As interest in the use of cannabinoids as adjunctive therapy for pain management has increased in the last decades (Hill et al., 2017), there has been a continuing need for an increase in cannabis research and bridging the knowledge gap about cannabis and its use in pain treatment. Therefore, research on cannabis and cannabinoids has increased dramatically in recent years. However, there are several obstacles that need to be overcome, such as the regulations and policies that restrict access to the cannabis products, funding limitations, and numerous methodological challenges (drug delivery, the placebo issue, etc.) (NASEM, 2017). This research is expected to explain and update the mechanisms of analgesic action of cannabis and its constituents, and to provide answers to questions about the safety of medicinal cannabis and its potential indications in the treatment of pain. Healthcare providers in all parts of the world must keep up to date with recent findings in order to provide valid information regarding the benefits, risks, and responsible medical use to patients in pain (Wilsey et al., 2016).

This article is a narrative review of the published preclinical and clinical research of the pharmacodynamics, pharmacokinetics, efficacy, safety and tolerability of cannabis/cannabinoids in the treatment of pain.

\section{MATERIALS AND METHODS}

In March 2018 we searched the MEDLINE database via PubMed (United States National Library of Medicine) for articles published up to March 1st, 2018 for the key words: 'cannabis' or 'cannabinoids' and 'pain' (in title/abstract). This was followed by filter species (humans/other animals) and language (English) selection. The abstracts of the 1270 citations extracted were screened for relevance by two reviewers (SV and DS). Discrepancies were resolved by discussion. The literature relevant to pharmacodynamic, pharmacokinetics, efficacy and safety of cannabis/cannabinoids in pain treatment was included. Both preclinical in vitro and in vivo data and clinical studies were included. Data on cannabis use among children, adolescents and pregnant women were excluded. We also examined the reference lists of reviewed articles.

\section{PHARMACODYNAMICS: CANNABIS AND CANNABINOIDS ACT ON MULTIPLE PAIN TARGETS}

For many years it was assumed that the chemical components of the cannabis plant, cannabinoids, produce analgesia by activating specific receptors throughout the body, in particular CB1, which are found predominantly in the CNS, and CB2, found predominantly in cells involved with immune function (Rahn and Hohmann, 2009). However, recently this picture has become much more complicated, as it has been recognized that cannabinoids, both plant-derived and endogenous, act simultaneously on multiple pain targets (Ross, 2003; Horvath et al., 2008; Pertwee et al., 2010; O'Sullivan, 2016; Morales et al., 2017) within the peripheral and CNS. Beside acting on cannabinoid $\mathrm{CB} 1 / \mathrm{CB} 2$ receptors, they may reduce pain through interaction with the putative non-CB1/CB2 cannabinoid $G$ protein-coupled receptor (GPCR) 55 (GPR55; Staton et al., 2008) or GPCR 18 (GPR18), also known as the $N$-arachidonoyl glycine (NAGly) receptor; Huang et al., 2001), and other well-known GPCRs, such as the opioid or serotonin (5-HT) receptors (Russo et al., 2005; Scavone et al., 2013). In addition, many studies have reported the ability of certain cannabinoids to modulate nuclear receptors (peroxisome proliferator-activated receptors (PPARs) (O’Sullivan, 2016), cys loop ligand-gated ion channels (Barann et al., 2002; Hejazi et al., 2006 Ahrens et al., 2009; Sigel et al., 2011; Xiong et al., 2011, 2012; Shi et al., 2012; Oz et al., 2014; 
Bakas et al., 2017) or transient receptor potential (TRP) channels (TRPV, TRPA, and TRPM subfamilies), (Pertwee et al., 2010; Lowin and Straub, 2015; Morales et al., 2017), among others. It has been shown that all these receptors represent potentially attractive targets for the therapeutic use of cannabinoids in the treatment of pain. Moreover, TRPV1 and CB1 or CB2 are colocalized at peripheral and/or central neurons (sensory neurons, dorsal root ganglia, spinal cord, brain neurons), which results in their intracellular crosstalk in situations where these receptors are involved simultaneously (Cristino et al., 2006; Anand et al., 2009). New data also demonstrate a variety of interactions between cannabinoid, opioid, and TRPV1 receptors in pain modulation (Zádor and Wollemann, 2015). All of these provide an opportunity for the development of new multiple target ligands and polypharmacological drugs with improved efficacy and devoid of side effects for the treatment of pain (Reddy and Zhang, 2013).

Several lines of evidence indicate that cannabinoids may contribute to pain relief through an anti-inflammatory action (Jesse Lo et al., 2005; Klein, 2005). In addition, non-cannabinoid constituents of the cannabis plant that belong to miscellaneous groups of natural products (terpenoids and flavonoids) may contribute to the analgesic, as well as the anti-inflammatory effects of cannabis (Andre et al., 2016; ElSohly et al., 2017).

Based on their origin, cannabinoids are classified into three categories: phytocannabinoids (plant-derived), endocannabinoids (present endogenously in human or animal tissues), and synthetic cannabinoids.

\section{Phytocannabinoids}

There are about 100 different cannabinoids isolated from the cannabis plant (Andre et al., 2016). The main psychoactive compound is (-)-trans- $\Delta 9$-tetrahydrocannabinol (THC), which is produced mainly in the flowers and leaves of the plant. The THC content varies from $5 \%$ in marijuana to $80 \%$ in hashish oil. THC is an analog to the endogenous cannabinoid, anandamide (ananda is the Sanskrit word for bliss; arachidonoylethanolamide, AEA). It is responsible for most of the pharmacological actions of cannabis, including the psychoactive, analgesic, antiinflammatory, anti-oxidant, antipruritic, bronchodilatory, antispasmodic, and muscle-relaxant activities (Rahn and Hohmann, 2009; Russo, 2011). THC acts as a partial agonist at cannabinoid receptors (CB1 and $\mathrm{CB} 2$ ) (Pertwee, 2008). A very high binding affinity of THC with the $\mathrm{CB} 1$ receptor appears to mediate its psychoactive properties (changes in mood or consciousness), memory processing, motor control, etc. It has been reported that a number of side effects of THC, including anxiety, impaired memory and immunosuppression, can be reversed by other constituents of the cannabis plant (cannabinoids, terpenoids, and flavonoids) (Russo and Guy, 2006; Russo, 2011; Andre et al., 2016).

The non-psychoactive analog of THC, cannabidiol (CBD), is another important cannabinoid found in the cannabis plant. It is thought to have significant analgesic, anti-inflammatory, anti-convulsant and anxiolytic activities without the psychoactive effect of THC (Costa et al., 2007). CBD has little binding affinity for either $\mathrm{CB} 1$ or $\mathrm{CB} 2$ receptors, but it is capable of antagonizing them in the presence of THC (Thomas et al., 2007). In fact, $\mathrm{CBD}$ behaves as a non-competitive negative allosteric modulator of $\mathrm{CB} 1$ receptor, and it reduces the efficacy and potency of THC and AEA (Laprairie et al., 2015). CBD also regulates the perception of pain by affecting the activity of a significant number of other targets, including non-cannabinoid GPCRs (e.g., 5-HT1A), ion channels (TRPV1, TRPA1 and TPRM8, GlyR), PPARs, while also inhibiting uptake of AEA and weakly inhibiting its hydrolysis by the enzyme fatty acid amide hydrolase (FAAH) (Russo et al., 2005; Staton et al., 2008; Ahrens et al., 2009; De Petrocellis et al., 2011; Burstein, 2015; Morales et al., 2017). It has been demonstrated that cannabidiol can act synergistically with THC and contribute to the analgesic effect of medicinal-based cannabis extract (Russo, 2011). At the same time, CBD displays an entourage effect (the mechanism by which non-psychoactive compounds present in cannabis modulate the overall effects of the plant), and is capable of improving tolerability and perhaps also the safety of THC by reducing the likelihood of psychoactive effects and antagonizing several other adverse effects of THC (sedation, tachycardia, and anxiety) (Russo and Guy, 2006; Abrams and Guzman, 2015). The differences in concentration of THC and CBD in the plant reflect the differences in the effects of different cannabis strains. Although CBD as a monotherapy in the treatment of pain has not been evaluated clinically, its antiinflammatory (Ko et al., 2016) and anti-spasmodic benefits and good safety profile suggest that it could be an effective and safe analgesic (Wade et al., 2003).

Other phytocannabinoids that can contribute to the overall analgesic effects of medical cannabis are cannabichromene $(\mathrm{CBC})$, cannabigerol (CBG), tetrahydrocannabivarin (THCV), and many others (Morales et al., 2017). Similarly to CBD, these compounds do not display significant affinities for cannabinoid receptors, but they have other modes of action. This is a new area of research that needs to be addressed (Piomelli et al., 2017).

\section{Endocannabinoid System}

This system seems to regulate many functions in the body, including learning and memory, mood and anxiety, drug addiction, feeding behavior, perception, modulation of pain and cardiovascular functions. The endocannabinoid system consists of cannabinoid receptors, endogenous cannabinoids (endocannabinoids), transport proteins and enzymes that synthesize or degrade the endocannabinoids.

Cannabinoid $\mathrm{CB} 1$ and $\mathrm{CB} 2$ receptors are 7-transmembrane G-protein coupled receptors (GPCRs). They play an important role in peripheral, spinal, and supraspinal nociception, including ascendant and descendent pain pathways (Hill et al., 2017). The signal transduction pathway of $\mathrm{CB} 1$ and $\mathrm{CB} 2$ involves inhibition of adenylyl cyclase, decreased cAMP formation, as well as an increase in the activity of mitogen-activated protein kinases (MAPK) (Ibsen et al., 2017). New evidence is emerging that different ligands can differentially activate these pathways, suggesting biased signaling through the cannabinoid receptors CB1 and CB2 (Ibsen et al., 2017).

The $\mathrm{CB} 1$ receptor is distributed throughout the nervous system. It mediates psychoactivity, pain regulation, memory processing and motor control. $\mathrm{CB} 1$ is a presynaptic 
heteroreceptor that modulates neurotransmitter and neuropeptide release and inhibits synaptic transmission. Activation of $\mathrm{CB} 1$ results in the activation of inwardly rectifying potassium channels, which decrease presynaptic neuron firing, and in the inhibition of voltage-sensitive calcium channels that decrease neurotransmitter release (Morales et al., 2017). The CB1 receptor is strategically located in regions of the peripheral and CNS where pain signaling is intricately controlled, including the peripheral and central terminals of primary afferent neurons, the dorsal root ganglion (DRG), the dorsal horn of the spinal cord, the periaqueductal gray matter, the ventral posterolateral thalamus and cortical regions associated with central pain processing, including the anterior cingulate cortex, amygdala and prefrontal cortex (Hill et al., 2017). The principal endogenous ligand for the $\mathrm{CB} 1$ receptor is AEA. $\mathrm{CB} 1$ receptors are observed more often on the gamma-aminobutyric acid (GABA) inhibitory interneurons in the dorsal horn of the spinal cord, and weakly expressed in most excitatory neurons (Hill et al., 2017). CB1 receptors are also present in multiple immune cells such as macrophages, mast cells and epidermal keratinocytes.

The CB2 receptor is found predominantly at the periphery (in tissues and cells of the immune system, hematopoietic cells, bone, liver, peripheral nerve terminals, keratinocytes), but also in brain microglia (Abrams and Guzman, 2015). The receptors are responsible for the inhibition of cytokine/chemokine release and neutrophil and macrophage migration and they contribute to slowing down of chronic inflammatory processes and modulate chronic pain (Niu et al., 2017). Both CB2 and CB1 receptors on mast cells participate in the anti-inflammatory mechanism of action of cannabinoids (Facci et al., 1995; SmallHoward et al., 2005). Also, activation of CB2 receptors on keratinocytes stimulates the release of $\beta$-endorphin, which acts at $\mu$ opioid receptors on peripheral sensory neurons to inhibit nociception (Ibrahim et al., 2005). Under basal conditions, CB2 receptors are present at low levels in the brain, the spinal cord and DRG, but may be upregulated in microglia where they modulate neuroimmune interaction in inflammation and after peripheral nerve damage (Hsieh et al., 2011). CB2 receptor activation inhibits adenylyl cyclase activity and stimulates MAPK activity, but the effect on calcium or potassium conductance is controversial (Rahn and Hohmann, 2009; Atwood et al., 2012). Stimulation of CB2 receptors does not produce cannabis-like effects on the psyche and circulation. The principal endogenous ligand for the CB2 receptor is 2-arachidonoylglycerol (2-AG) (Kano, 2014).

Endocannabinoids are arachidonic acid derivatives. AEA and 2-AG are synthesized separately, they have local (autocrine and paracrine) effects and are rapidly removed by hydrolysis by fatty acid amide hydrolase (FAAH) and monoacylglycerol lipase (MAGL), respectively (Pacher et al., 2006; Starowicz and Przewlocka, 2012; Howard et al., 2013). Beside AEA, FAAH inhibition significantly elevates the levels of other fatty-acid amides such as oleoylethanolamide (OEA) and palmitoylethanolamide (PEA) in the CNS and peripheral tissues (Lambert et al., 2002). Endocannabinoids, similarly to THC, appear to activate cannabinoid receptors. AEA and 2-AG are a partial and full agonist of CB receptors, respectively (Kano, 2014).
They work as a part of a negative feedback loop that regulates neurotransmitter and neuropeptide release and thereby modulate various CNS functions, including pain processing (Vaughan and Christie, 2005).

The AEA is a full agonist at TRPV1 (AEA referred to as an 'endovanilloid') that activates TRPV1 which results in desensitization (Ross, 2003; Horvath et al., 2008; Starowicz and Przewlocka, 2012). AEA also activates GR55 (Ryberg et al., 2007), directly inhibits 5-HT3A receptors (Barann et al., 2002) potentiates the function of glycine receptors (Hejazi et al., 2006), inhibits T-type voltage-gated calcium channels (Chemin et al., 2001) and activates PPARs (Rockwell and Kaminski, 2004; Sun et al., 2007; Romano and Lograno, 2012; O’Sullivan, 2016).

Endocannabinoids, which are produced in neural and nonneural cells in the physiological response to tissue injury or excessive nociceptive signaling, suppress inflammation, sensitization and pain (Piomelli and Sasso, 2014; Maccarrone et al., 2015). Inhibitors of FAAH lead to elevated AEA levels and are intended for therapeutic use (Hwang et al., 2010). $N$-acylethanolamines such as PEA and OEA do not belong to endocannabinoids as they do not bind to cannabinoid receptors; they exhibit anti-inflammatory action via PPARs, and also inhibit pain through TRPV1 receptors. They are of interest to the field of cannabinoid pain research as they elevate levels of AEA through substrate competition at FAAH (Lambert et al., 2002).

There is a constant active exchange of substrates and metabolites between endocannabinoid and eicosanoid pathways. The enzyme FAAH breaks down AEA to arachidonic acid and ethanolamine or, alternatively, AEA can be directly transformed by cyclooxygenase-2 (COX-2) into proalgesic prostaglandins. As such, AEA may contribute to the analgesic properties of COX-2 selective NSAIDs. It was established that the metabolite of paracetamol combines with arachidonic acid by the action of FAAH to produce an endocannabinoid, which is a potent agonist at the TRPV1 and a weak agonist at both CB1 and CB2 receptors and an inhibitor of AEA reuptake (Bertolini et al., 2006).

\section{Synthetic Cannabinoids}

At present, there are two synthetic cannabinoids on the market, dronabinol and nabilone, which may be of benefit in the treatment of pain (Abrams and Guzman, 2015). In general, their use in pain treatment is off-label. Dronabinol is a generic name for the oral form of synthetic THC (Marinol $\left.{ }^{\circledR}\right)$. It is approved for the treatment of chemotherapy-associated nausea and vomiting, and anorexia associated with human immunodeficiency virus infection. Nabilone, a generic name for the orally administered synthetic structural analog of THC (Cesamet ${ }^{\circledR}$ ), is approved for the treatment of chemotherapy-associated nausea and vomiting. Their medical use is mostly limited by their psychoactive side effects, as well as their limited bioavailability (Huestis, 2007).

\section{Cannabis and Cannabis Extract}

Cannabis delivered by way of inhalation (smoked or inhaled through vaporization), orally or oromucosally, produces a host of biological effects (Andre et al., 2016). Unfortunately, clinical 
trials conducted on cannabis are limited, and no drug agency has approved the use of cannabis as a treatment for any medical condition. Although there is no formal approval, cannabis is widely used for the treatment of pain. It is authorized by physicians where medical marijuana is legal (Health Canada, 2013).

Nabiximols, a generic name for the whole-plant extract with a 1:1 ratio of THC:CBD (2.7 THC $+2.5 \mathrm{CBD}$ per $100 \mu \mathrm{L})$, an oromucosal spray $\left(\right.$ Sativex ${ }^{\circledR}$ ) is approved as an adjuvant treatment for symptomatic relief of spasticity in adult patients with multiple sclerosis (MS) who have not responded well to other therapy and who have demonstrated a significant improvement during an initial trial of Sativex ${ }^{\circledR}$ therapy. In addition, Sativex ${ }^{\circledR}$ is approved in Canada (under the Notice of Compliance with Conditions) as an adjuvant treatment for symptomatic relief of neuropathic pain in adults with MS, and as an adjuvant analgesic in adult patients with advanced cancer who suffer from moderate to severe pain that is resistant to strong opioids (Health Canada, 2013). An approval under the Notice of Compliance with Conditions means that a product shows potential benefit, possesses high quality and an acceptable safety profile based on a benefit-risk evaluation (Portenoy et al., 2012). Nabiximols is also approved in the United Kingdom and some European countries (e.g., Spain). The United States Food and Drug Administration (FDA) has not yet approved nabiximols as a treatment for any medical condition. Currently it is under investigation by the FDA under the Investigational New Drug Application (IND) for the treatment of cancer pain. Beside THC and CBD, nabiximols also contains other cannabinoids, terpenoids, and flavonoids.

\section{PHARMACOKINETICS OF CANNABIS/CANNABINOIDS}

Cannabis is mostly inhaled by smoking and to a lesser extent by vaporization. The pharmacokinetics of inhaled and oral cannabis differ significantly (Agurell et al., 1986; Huestis, 2007). Taken by mouth, THC is metabolized in the liver to 11-hydroxy-THC, a potent psychoactive metabolite. By inhalation, cannabis (THC) avoids the first passage metabolism in the liver, and the effect of inhaled cannabis is proportionate to the plasma levels of THC. The pharmacokinetic profile of the inhaled cannabis is similar to THC given by the intravenous route (Agurell et al., 1986). The pharmacokinetic profile of CBD is very similar to THC given by the same route of administration.

When inhaled, cannabinoids are rapidly absorbed into the bloodstream. The advantages of inhaled over oral cannabis are the fast onset of action (requiring minutes instead of hours), and rapid attainment of peak effect (in $1 \mathrm{~h}$ vs. several hours), which is maintained at a steady level for 3-5 h (vs. the variable effect, observed after oral administration, which lasts from 8 to more than $20 \mathrm{~h}$ ) and less generation of the psychoactive metabolite (Agurell et al., 1986). The analgesic effect is experienced shortly after the first breath and can be maximized by self-titration (patients adjust cannabis dosage themselves). However, self-titration of oral cannabis is not recommended due to the unpredictable appearance of side effects. The main disadvantage of smoking cannabis is inhalation of combustion byproducts with possible adverse effects in the respiratory tract (Volkow et al., 2014; NASEM, 2017). Therefore, vaporization is considered a better alternative for the inhalation of cannabis. About $25-27 \%$ of the available THC becomes available to the systemic circulation after smoking (Carter et al., 2004; Zuurman et al., 2009). The bioavailability of inhaled THC varies considerably, probably due to differences in inhalation techniques and source of the cannabis product (Agurell et al., 1986; Huestis, 2007).

Dronabinol, nabilone, and nabiximols are currently available oral pharmaceutical preparations of cannabinoids with standardized concentrations or doses. The main limitation associated with the administration of oral cannabinoids is their poor pharmacokinetic profile characterized by slow, unpredictable and highly variable absorption, late onset of action, extended duration due to psychoactive metabolites and unpredictable psychotropic effects (Ohlsson et al., 1980; Huestis, 2007; Issa et al., 2014). Oral THC (extract, synthetic or cannabis-derived) bioavailability was reported to be $6-20 \%$ only (Wall et al., 1983; Agurell et al., 1986). Further efforts are aimed at improving the bioavailability of oral cannabinoids (Smith, 2015).

Tetrahydrocannabinol is characterized by high binding to plasma protein (95-99\%) so that the initial volume of distribution of THC is equivalent to the plasma volume (Grotenhermen, 2003). However, the distribution changes over time, with the steady state volume of distribution being about $3.5 \mathrm{~L}$ per $\mathrm{kg}$ of body weight. This is due to the high lipophilicity of THC, with high binding to fat tissue. THC crosses the placental barrier and small amounts also cross into breast milk (Grotenhermen, 2003).

Tetrahydrocannabinol is metabolized by cytochrome $\mathrm{P} 450$ enzymes CYP 2C9, 2C19 and 3A4, (Huestis, 2007; Rong et al., 2018), and drugs that inhibit these enzymes (e.g., proton pump inhibitors, HIV protease inhibitors, macrolides, azole antifungals, calcium antagonists and some anti-depressants) can increase the bioavailability of THC. Conversely, drugs that induce hepatic enzymes responsible for THC metabolism (e.g., phenobarbital, phenytoin, troglitazone, and St John's wort) will lower its bioavailability (Rong et al., 2018).

In chronic-pain patients on opioid therapy, vaporized cannabis increases the analgesic effects of opioids without affecting significantly the plasma opioid levels (Abrams et al., 2011) suggesting that the effects are probably due to pharmacodynamic rather than pharmacokinetic interactions.

\section{CANNABINOIDS IN ANIMAL MODELS OF PAIN}

Behavioral studies have shown that synthetic or plant-derived cannabinoid receptor agonists or endogenous cannabinoid ligands are effective in different animal models of acute pain (Dhopeshwarkar and Mackie, 2014). However, data obtained in humans, including volunteers with experimental pain and clinical trial patients, suggest that cannabinoids may be more effective 
for chronic rather than acute pain conditions (Kraft et al., 2008). Also, a number of targets identified in animal studies have not been confirmed in clinical trials. These include the absence of apparent clinical activity in clinical trials with CB2 agonists (Roche and Finn, 2010; Ostenfeld et al., 2011; Atwood et al., 2012; Pereira et al., 2013; Dhopeshwarkar and Mackie, 2014). In addition, FAAH inhibitors, although providing promising data in animal studies, did not demonstrate a significant efficacy against chronic pain in humans (Huggins et al., 2012; Woodhams et al., 2017). These discrepancies may be explained by species differences, differences in methodology and outcomes measured in the studies, as well as lack of selectivity of the ligands used (Dhopeshwarkar and Mackie, 2014). On the other hand, the outcome of a clinical trial of pain depends on the type of pain, trial design, target patient population, and several other factors (Gewandter et al., 2014). The effect of THC and other cannabinoids acting at $\mathrm{CB} 1$ receptors on motor activity in animals may easily be misinterpreted as pain-suppressing behavior (Meng et al., 1998). In humans, multiple emotional and cognitive factors influence the perception and experience of pain and this result in high inter-individual variability. However, pain in animals is mainly measured as a behavioral response to noxious stimuli, so that results obtained from animal studies are often more consistent. Also, volunteers with experimental pain respond more uniformly than patients with pathological pain, and pain pathways in healthy volunteers differ from those in patients (Olesen et al., 2012).

Due to CB1 receptor activation, the cannabinoid antinociception in animals may be accompanied by CNS side effects (e.g., hypoactivity, hypothermia and catalepsy) (Martin et al., 1991), which may translate into psychoactive side effects in humans (e.g., drowsiness, dizziness, ataxia, and fatigue).

A growing body of evidence indicates that in the treatment of chronic pain conditions, stimulation of the endocannabinoid system presents a promising approach that may prevent the occurrence of CNS side effects (Lomazzo et al., 2015). Several new strategies on how to preserve analgesic activity and avoid psychoactivity of cannabinoids have been proposed and tested in animals. They include inhibition of endocannabinoid uptake and metabolism in identified tissues where increased levels of endocannabinoids are desirable, administration of novel compounds that selectively target peripheral $\mathrm{CB} 1$ and CB2 receptors, positive allosteric modulation of cannabinoid $\mathrm{CB} 1$ receptor signaling, and modulation of non-CB1/non-CB2 receptors (TRPV1, GPR55, and PPARs) (Malek and Starowicz, 2016; Starowicz and Finn, 2017). In recent years, dual-acting compounds that provide FAAH inhibition (increased AEA and decreased arachidonic acid levels), TRPV1 antagonism (that prevents activation of the pro-nociceptive pathway by AEA), or COX-2 inhibition (that increases AEA and decreases prostaglandin levels), have offered the most promising results in chronic pain states in animals (Maione et al., 2007; Grim et al., 2014; Morera et al., 2016; Malek and Starowicz, 2016; Aiello et al., 2016; Starowicz and Finn, 2017). However, it is important to verify whether the efficacy of this multitarget strategy observed in rodent models of chronic pain and inflammation translates to humans and is not speciesspecific.

\section{Neuropathic Pain}

Cannabinoids have been studied in various types of neuropathic pain in animals, including chronic nerve constriction traumatic nerve injury, trigeminal neuralgia, chemotherapy- and streptozotocin-induced neuropathy, etc.

Both $\mathrm{CB} 1$ and $\mathrm{CB} 2$ receptors have been found to be upregulated in nervous structures involved in pain processing in response to peripheral nerve damage (Lim et al., 2003; Zhang et al., 2003; Hsieh et al., 2011), and this may explain the beneficial effects of cannabinoid receptor agonists on neuropathic pain. It has been shown that increased CB2 expression is accompanied by the appearance of activated microglia (Zhang et al., 2003). Both microglial activation and neuropathic pain symptoms can be suppressed by CB2 agonists (Wilkerson et al., 2012). Consistent with this, CB2 knockout mice and transgenic mice overexpressing CB2 are characterized by enhanced and suppressed reactivity of microglia and neuropathic pain symptoms, respectively (Racz et al., 2008). TRPV1 expression is also increased in glutamatergic neurons of the medial prefrontal cortex in a model of spared nerve injury (SNI) in rats (Giordano et al., 2012).

In different neuropathic pain conditions, systemic administration of synthetic mixed cannabinoid CB1/CB2 agonists produces antinociceptive effects similar to those of THC (Herzberg et al., 1997; Pascual et al., 2005; Liang et al., 2007). The CB2 selective agonists given intrathecally or systemically are also effective in several animal models of neuropathic pain (Yamamoto et al., 2008; Kinsey et al., 2011), but their antinociceptive effects are without development of tolerance, physical withdrawal and other CNS side effects that accompany CB1 agonism (Deng et al., 2015).

When given early in the course of diabetes, $\mathrm{CBD}$ attenuates microgliosis in the ventral lumbar spinal cord of diabetic mice, as well as tactile allodynia and thermal hyperalgesia. However, if given later in the course of the disease, CBD has a little effect on pain-related behavior (Toth et al., 2010).

A controlled cannabis extract containing numerous cannabinoids and other non-cannabinoid fractions such as terpenes and flavonoids demonstrated greater antinociceptive efficacy than the single cannabinoid given alone, indicating synergistic antinociceptive interaction between cannabinoids and non-cannabinoids in a rat model of neuropathic pain (Comelli et al., 2008). The anti-hyperalgesic effect did not involve the cannabinoid receptors but was mediated by TRPV1 and thus it most probably belongs to CBD.

In animals with neuropathic pain, increased levels of endocannabinoids (AEA and 2-AG) have been detected in different regions of the spinal cord and brain stem (Mitrirattanakul et al., 2006; Petrosino et al., 2007). However, they appeared to be differentially regulated in different models of neuropathic pain, depending on the characteristic of the pain and the affected tissues (Starowicz and Przewlocka, 2012). Genetic or pharmacological inactivation of FAAH/MAGL resulting in the elevation of endocannabinoid (AEA/2-AG) 
levels in the spinal cord and brain stem (Lichtman et al., 2004; Schlosburg et al., 2009; Long et al., 2009; Adamson Barnes et al., 2016) show promise for suppressing both neuropathic and inflammatory pain. In general, the antinociceptive effect of endocannabinoids is sensitive to antagonists of CB1 and CB2 receptors, TRPV1 channels and PPAR $\alpha$ antagonism, indicating that multiple targets could be involved in the mechanism of their action (Kinsey et al., 2010; Caprioli et al., 2012; Piomelli, 2014; Adamson Barnes et al., 2016). The reduction in the side effects that accompany CB1 agonism, such as motor incoordination, catalepsy, sedation and hypothermia, suggests that mainly TRPV1, but not a cannabinoid receptor-dependent mechanism, mediate the analgesic properties of exogenously and endogenously elevated levels of AEA in neuropathic pain. In a rat chronic constriction injury (CCI) model, depending on the dose of URB597 (FAAH inhibitor) used, lower or higher elevation of endogenous AEA levels and CB1- or TRPV1-mediated analgesia were achieved, respectively (Starowicz et al., 2012). It has been suggested that endocannabinoids can increase the excitability of nociceptive neurons by reducing synaptic release of inhibitory neurotransmitters via $\mathrm{CB} 1$ receptors on dorsal horn neurons (Pernía-Andrade et al., 2009), as well as by agonist activity on TRPV1 (Ross, 2003).

Monoacylglycerol lipase inhibitors demonstrated CB1dependent behavioral effects, including analgesia, hypothermia and hypomotility (Long et al., 2009). In a mouse model of neuropathic pain both $\mathrm{CB} 1$ and $\mathrm{CB} 2$ were engaged in the anti-allodynic effects of FAAH inhibitors, while only CB1 was involved in the anti-allodynic effect of the MAGL inhibitor (Kinsey et al., 2010). Also, unlike FAAH inhibitors, the persistent blockade of MAGL activity leads to desensitization of brain $\mathrm{CB} 1$ receptors and loss of the analgesic phenotype (Chanda et al., 2010) and physical dependence (Schlosburg et al., 2009). However, a new highly selective MAGL inhibitor, KML29, exhibited antinociceptive activity without cannabimimetic side effects (Ignatowska-Jankowska et al., 2014).

In CCI in mice, JZL195, a dual inhibitor of FAAH and MAGL, demonstrated greater anti-allodynic efficacy than selective FAAH or MAGL inhibitors, and a greater therapeutic window (less motor incoordination, catalepsy and sedation) than WIN55212, a cannabinoid receptor agonist (Adamson Barnes et al., 2016).

Co-administration of sub-threshold doses of FAAH inhibitor, PF-3845 and the non-selective COX inhibitor, diclofenac sodium, produced enhanced antinociceptive effects in rodent models of both neuropathic (CCI) and inflammatory pain (intraplantar carrageenan) (Grim et al., 2014). Combined FAAH inhibition/TRPV1 antagonism is also an attractive therapeutic strategy because FAAH inhibition only produced biphasic effects, with antinociception via CB1 at low levels of AEA, and when AEA levels were higher, pronociceptive effects via TRPV1 (Maione et al., 2007; Malek and Starowicz, 2016).

Cannabinoids may attenuate neuropathic pain by peripheral action via both CB1 and/or CB2 receptors (Fox et al., 2001; Elmes et al., 2004). The peripherally acting cannabinoid agonist AZ11713908 reduced mechanical allodynia with a similar efficacy to WIN55,212-2, an agonist that entered the CNS (Yu et al., 2010). In addition, URB937, a brain impermeant inhibitor of FAAH, elevated anandamide outside the brain and controlled neuropathic pain behavior without producing CNS side effects (Clapper et al., 2010).

After identification of allosteric binding site(s) on the CB1 GPCR (Price et al., 2005), several CB1-positive allosteric modulators have been developed and tested in animals. They attenuated both inflammatory and neuropathic pain behavior without producing the CB1-mediated side effects of orthosteric CB1 agonists but did not produce tolerance after repeated administration (Khurana et al., 2017; Slivicki et al., 2017).

\section{Inflammatory Pain}

Different classes of cannabinoids (i.e., CB1 agonists, CB2 agonists, mixed $\mathrm{CB} 1 / \mathrm{CB} 2$ agonists, endocannabinoids and endocannabinoid modulators) all suppressed pain behavior in various animal models of inflammatory pain (Clayton et al., 2002; Burgos et al., 2010; Starowicz and Finn, 2017). Since inflammatory pain is a characteristic of several chronic diseases, including cancer, arthritis, inflammatory bowel disease, sicklecell disease, etc., cannabinoids appear to promise the lessening of severe pain in these diseases (Fichna et al., 2014; Abrams and Guzman, 2015; Turcotte et al., 2016; Vincent et al., 2016).

It is well known that CB2 receptor expression increases in microglia in response to inflammation and serves to regulate neuroimmune interactions and inflammatory hyperalgesia (Dhopeshwarkar and Mackie, 2014). However, the extent of CB2 expression in neurons is a subject of controversy (Atwood and Mackie, 2010; Atwood et al., 2012). It has been suggested that peripheral inflammation, unlike peripheral nerve injury, does not induce $\mathrm{CB} 2$ receptor expression in the spinal cord (Zhang et al., 2003). In contrast, Hsieh et al. (2011) demonstrated that the CB2 receptor gene is significantly upregulated in DRG and paws ipsilateral to inflammation induced by injection of complete Freund's adjuvant (CFA).

Systemic or local peripheral injection of the CB2-selective agonist was reported to reduce nociceptive behavior and swelling in different animal models of inflammation (Quartilho et al., 2003; Elmes et al., 2005; Kinsey et al., 2011). In addition, the CB2-selective agonist did not produce hypothermia or motor deficit that are CB1-mediated side effects (Kinsey et al., 2011). Therefore, a CB2 receptor selective agonist is expected to have less psychomimetic side effects and lower abuse potential as compared to the available non-selective or CB1-selective cannabinoid agonists. In animal models of inflammatory disease, CB2 agonists slow the progression of diseases (Turcotte et al., 2016). In a murine model of rheumatoid arthritis, collageninduced arthritis (CIA), CB2-selective agonists did not prevent the onset of arthritis, but did ameliorate established arthritis (Sumariwalla et al., 2004). JWH133, a selective CB2 agonist, inhibited in vitro production of cytokines in synoviocytes and in vivo reduced the arthritis score, inflammatory cell infiltration and bone destruction in CIA (Fukuda et al., 2014). Another CB2selective agonist, HU-308, was shown to reduce swelling, synovial inflammation and joint destruction, in addition to lowering circulating antibodies against collagen I in CIA (Gui et al., 2015). Although approved in a range of preclinical models of 
pain, LY2828360, CB2 agonist, failed in a trial of patients with osteoarthritic knee pain (Pereira et al., 2013).

It was shown that formalin administration to the hind paw of rats induced AEA release into the periaqueductal gray matter (Walker et al., 1999). FAAH knockout mice and mice that express FAAH exclusively in nervous tissue, displayed anti-inflammatory and anti-hyperalgesic effects in both the carrageenan and CIA models, and the effects were prevented by administration of a CB2 but not a CB1 antagonist (Lichtman et al., 2004; Kinsey et al., 2011). FAAH inhibition may also reduce nociceptive behavior induced by lipopolysaccharide injection into the rat hind paw, and examination of the mechanism showed that both CB1 and CB2 were involved, but not TRPV1, PPARs, or opioid receptors (Booker et al., 2012). Oral administration of PF-04457845, a highly efficacious and selective FAAH inhibitor, produced potent antinociceptive effects in the CFA model of arthritis in rats, and it was shown that both $\mathrm{CB} 1$ and $\mathrm{CB} 2$ receptors were implicated in this effect (Ahn et al., 2011). In contrast to animal data, PF04457845 failed to demonstrate efficacy in a randomized placebo and active-controlled clinical trial on pain in osteoarthritis of the knee (Ahn et al., 2011; Huggins et al., 2012). The possible explanations are development of tolerance to chronically elevated endocannabinoids or sensitization of TRPV1 receptors. A pronociceptive phenotype has been recently documented in FAAH knockout mice after administration of a challenge dose of TRPV1 agonist capsaicin (Carey et al., 2016). The increased nociceptive response was attenuated by antagonists of CB1 and TRPV1 receptors.

In a recent phase I trial, the FAAH inhibitor BIA-102474 caused death in one and severe neurological damage in five participants (Kaur et al., 2016; Moore, 2016). It has been suggested that specificity and non-selectivity of this molecule and several errors in the design of the study were responsible for its toxicity, and not targeting of FAAH per se (Huggins et al., 2012; Pawsey et al., 2016). More research is necessary to characterize both the efficacy and safety profiles of endocannabinoid-directed therapeutic strategies.

An increase in local endocannabinoid levels by inhibition with local peripheral administration of URB597 (an irreversible FAAH inhibitor) induced analgesia in a model of carrageenan-induced inflammation in rats that was inhibited by a PPAR $\alpha$ antagonist but not by a CB1 receptor antagonist (Sagar et al., 2008). However, local administration of URB597 into osteoarthritic knee joints reduced pain via $\mathrm{CB} 1$ receptors [monosodium iodoacetate (MIA)-induced osteoarthritis in rats and the model of spontaneous osteoarthritis in Dunkin-Hartley guinea pigs] (Schuelert et al., 2011). A peripherally restricted FAAH inhibitor, URB937, also reduced inflammatory pain in rodents via $\mathrm{CB} 1$ receptors (Clapper et al., 2010).

It was shown that inhibition of fatty acid binding proteins (FABPs) reduced inflammatory pain in mice. This effect was associated with an upregulation of AEA and the effect was inhibited by antagonists of CB1 or PPAR $\alpha$ receptors (Kaczocha et al., 2014).

Recent animal findings suggest that cannabinoids may have beneficial effect on affective-emotional and cognitive aspect of chronic pain (La Porta et al., 2015; Neugebauer, 2015;
Kiritoshi et al., 2016). In mice with MIA-induced arthritis, selective agonists of both $\mathrm{CB} 1$ and $\mathrm{CB} 2$ receptors ameliorated the nociceptive and affective manifestations of osteoarthritis, while a CB1-selective agonist improved the memory impairment associated with arthritis (La Porta et al., 2015; Woodhams et al., 2017). This is in agreement with human studies of cannabinoids that indicate a significant improvement in secondary outcome measures, such as sleep and mood (Lynch and Ware, 2015).

The combined FAAH/COX inhibitor ARN2508 demonstrated efficacy against intestinal inflammation and was without gastrointestinal side effects (Sasso et al., 2015) because AEA, which is similar to prostanoids, has protective actions on the gastrointestinal mucosa.

\section{Cancer Pain}

Experiments with animal models of cancer pain support the use of cannabinoids in the treatment of cancer pain in humans. Systemic administration of non-selective, CB1 selective or CB2 selective agonist significantly attenuated mechanical allodynia in a mouse model which was produced by inoculating human oral cancer cell lines HSC3 into the hind-paw of mice (Guerrero et al., 2008). A mechanical hyperalgesia associated with decreased anandamide levels were found in plantar paw skin ipsilateral to tumor induced by injection of fibrosarcoma cells into the calcaneum of mice. The paw withdrawal frequency was reduced after local injection of anandamide (Khasabova et al., 2008). Also, one study reported that the efficacy of synthetic CB1and CB2-receptor agonists was comparable with the efficacy of morphine in a murine model of tumor pain (Khasabova et al., 2011). An important finding is that cannabinoids are effective against neuropathic pain induced by exposure of animals to anticancer chemotherapeutics (vincristine, cisplatin, paclitaxel) (Rahn et al., 2007; Khasabova et al., 2012; Ward et al., 2014).

\section{CLINICAL TRIALS OF CANNABIS/CANNABINOIDS IN CHRONIC PAIN}

Pain relief is the most commonly cited reason for the medical use of cannabis. In 2011, 94\% of the registrants on the Medical Marijuana Use Registry in Colorado (United States) were using medical marijuana for chronic pain (Kondrad and Reid, 2013). However, cannabis is not the first drug of choice that a patient takes to relieve pain. As with many other analgesics, cannabinoids do not seem to be equally effective in the treatment of all pain conditions in humans. This is most probably due to the different mechanisms of pain (e.g., acute vs. chronic, or chronic noncancer vs. chronic cancer pain) (Romero-Sandoval et al., 2017). Clinical studies have shown that cannabinoids are not effective against acute pain (Buggy et al., 2003; Beaulieu, 2006; Holdcroft et al., 2006; Kraft et al., 2008). Clinical data also indicate that cannabinoids may only modestly reduce chronic pain, like all presently available drugs for the treatment of chronic pain in humans (Romero-Sandoval et al., 2017). 


\section{Efficacy of Cannabis/Cannabinoids in the Treatment of Chronic Pain}

Until recently, there was no consensus about the role of cannabinoids for the treatment of chronic pain. Several years ago, the European Federation of Neurological Societies recommended cannabinoids (THC, oromucosal sprays $2.7 \mathrm{mg}$ delta-9-tetrahydrocannabinol/2.5 $\mathrm{mg}$ cannabidiol) as the second or third line of treatment of central pain in MS (Attal et al., 2010). More recently, the Canadian Pain Society supported their use as the third-line option for the treatment of neuropathic pain, after anti-convulsives, anti-depressants, and opioids (Moulin et al., 2014). In addition, Health Canada provided preliminary guidelines for prescribing smoked cannabis in the treatment of chronic non-cancer pain (Kahan et al., 2014). At the same time, the Special Interest Group on neuropathic pain of the International Association for the Study of Pain provided "a weak recommendation against the use of cannabinoids in neuropathic pain, mainly because of negative results, potential misuse, abuse, diversion and long-term mental health risks particularly in susceptible" (Finnerup et al., 2015).

There is a growing body of evidence to support the use of medicinal cannabis in the treatment of chronic pain. At present, there is a scientific consensus on the medicinal effects of cannabis for the treatment of chronic pain that is based on scientific evidence. The National Academy of Sciences, Engineering and Medicine (NASEM, 2017) has evaluated more than 10,000 scientific abstracts and established that there is "conclusive or substantial evidence" for the use of cannabis in treating chronic pain in adults. Also, there is "moderate evidence" that cannabinoids, in particular nabiximols, are effective in improving short-term sleep outcomes in patients with chronic pain (NASEM, 2017). The expert report NASEM supports more research to determine dose-response effects, routes of administration, side effects and risk-benefit ratio of cannabis/cannabinoid use with precision and make possible evidence based policy measure implementation. At the same time, the PDQ Integrative Alternative and Complementary Therapies Editorial Board (2018) states that pain relief is one of the potential benefits of cannabis/cannabinoids for people living with cancer (in addition to its anti-emetic effects, appetite stimulation, and improved sleep).

\section{Chronic Non-cancer Pain}

Lynch and Campbell (2011) and Lynch and Ware (2015) performed two systematic reviews of cannabis/cannabinoid use in chronic non-cancer pain (neuropathic pain, fibromyalgia, rheumatoid arthritis and mixed chronic pain) involving 18 randomized controlled trials published between 2003 and 2010, and 11 studies published between 2011 and 2014, respectively. All 29 trials included about 2000 participants and their duration was up to several weeks. Twenty-two of 29 trials demonstrated a significant analgesic effect and several also reported improvements in secondary outcomes (sleep, spasticity).

Whiting et al. (2015) performed a systematic review of the benefits and adverse events of orally administered cannabinoids and inhaled cannabis for a variety of indications (chronic pain was assessed in 28 studies, there were 2454 participants, the follow-up period lasted up to 15 weeks), and provided moderatequality evidence to support the use of cannabinoids for the treatment of chronic pain.

The Canadian Agency for Drugs and Technologies in Health (2016) recently analyzed five systematic reviews (including two with meta-analyses) of nabiximols (THC:CBD buccal spray) for the treatment of chronic non-cancer or neuropathic pain (Lynch and Campbell, 2011; Lynch and Ware, 2015; Jawahar et al., 2013; Boychuk et al., 2015; Whiting et al., 2015). The length of the follow-up across the studies was from 1 to 15 weeks. In this review, there are inconsistencies with regard to both the effectiveness and safety of nabiximols. The authors concluded that treatment with nabiximols in the short term may be associated with pain relief and good tolerability when compared with placebo therapy, but there is still insufficient evidence to support its use in the management of chronic neuropathic and non-cancer pain.

\section{Neuropathic pain}

Cannabis. The meta-analysis of individual patient data from 5 randomized trials (178 participants) presents evidence that inhaled cannabis may provide short-term reductions $(>30 \%$ reduction in pain scores) in chronic neuropathic pain (diabetes, HIV, trauma) for 1 in 5-6 patients (Andreae et al., 2015). In these trials, the THC content ranged from 3.5 to $9.4 \%$. A doserelated effect of cannabis was found, with higher THC contents producing more pronounced pain relief. In one study, pain relief was not dose-dependent and was achieved with a low concentration of cannabis THC [1.29\% (vaporized)] (Wilsey et al., 2013). The follow-up periods ranged from days to weeks. Consistent with the results of this meta-analysis, a more recent, small, randomized, double-blind, placebo-controlled crossover clinical study demonstrated that vaporized cannabis (1-7\% THC) in a dose-dependent manner reduced spontaneous and evoked pain in patients (16 subjects) suffering from painful diabetic neuropathy (Wallace et al., 2015). The analgesic effect was achieved at THC concentrations as low as $1-4 \%$. In a more recent randomized, placebo-controlled, double-blind crossover study (38-41 participants per group), Wilsey et al. (2016) reported that low THC concentrations (2.9-6.7\%) of vaporized cannabis effectively reduced chronic neuropathic pain after spinal cord injury or disease. It was found that higher plasma levels of THC and/or the THC metabolite significantly correlated with improvements in clinical symptoms of pain (Wilsey et al., 2016).

Oral cannabinoids. No recommendations regarding cannabinoid treatment of non-spastic and non-trigeminal neuralgic pain in adult patients with MS were reported in the systemic review of Jawahar et al. (2013). Results of another systematic review that analyzed the effectiveness of cannabis extracts and cannabinoids in the treatment of chronic non-cancer neuropathic pain suggested that cannabis-based medicinal extracts may provide pain relief in conditions that are refractory to other treatments (Boychuk et al., 2015). It was pointed out that further studies are required to estimate the influence of the duration of the treatment. 
A recently published systematic review (Meng et al., 2017) considered 11 randomized controlled studies involving a total of 1219 participants in which oral cannabinoids (dronabinol, nabilone, and nabiximols) were compared with standard pharmacological and/or non-pharmacological treatments or placebo in patients with neuropathic pain (including MS). This study shows that oral cannabinoids are modestly effective in reducing chronic neuropathic pain and that for this effect a minimum of 2 weeks of treatment is required. The study also showed improvements in the quality of life, sleep and increased patient satisfaction. However, the quality of the evidence is moderate and the strength of recommendation for analgesic efficacy of selective cannabinoids in this clinical setting is weak. Of the different cannabinoids used, nabiximols and dronabinol but not nabilone demonstrated an analgesic advantage.

The authors of the most recent Cochrane Review on the efficacy, tolerability and safety of cannabis-based medicines (CBM; botanical, plant-derived, and synthetic) compared to placebo or conventional drugs for neuropathic pain in adults (16 randomized, double-blind controlled trials with 1750 participants) concluded that the potential benefits of CBM in neuropathic pain might be outweighed by their potential harms (Mücke et al., 2018). All CBMs were superior to placebo in reducing pain intensity, sleep problems and psychological distress (very low- to moderate-quality evidence). Between these two groups, no differences were found in improvements to health-related quality of life and discontinuation of the medication because of its ineffectiveness. There was no difference between CBM and placebo in the frequency of serious adverse events (low-quality evidence). Adverse events were reported by $80.2 \%$ of participants in the CBM group and $65.6 \%$ of participants in the placebo group (RD 0.19 , 95\% CI $0.12-$ $0.27 ; P$-value $\left.<0.0001 ; I^{2}=64 \%\right)$. CBM may increase nervous-system adverse events compared with placebo [61\% vs. $29 \%$; RD 0.38 (95\% CI 0.18-0.58); number-needed-toharm (NNTH) 3 (95\% CI 2-6); low-quality evidence], as well as psychiatric disorders (17\% vs. 5\%: RD 0.10 (95\% CI 0.06-0.15); NNTH 10 (95\% CI 7-16); low-quality evidence]. Some of the adverse events (e.g., somnolence, sedation, confusion, and psychosis) may limit the clinical usefulness of CBM.

\section{Rheumatic pain}

Four randomized controlled trials with 159 patients with fibromyalgia, osteoarthritis, chronic back pain and rheumatoid arthritis treated with cannabinoids (nabilone, nabiximols, and FAAH inhibitor) or placebo or an active control (amitriptyline), were included in a systemic review (Fitzcharles et al., 2016). The results were not consistent and did not reveal whether the cannabinoids were superior to the controls (placebo and amitriptyline). The authors concluded that there is insufficient evidence for the recommendation for cannabinoid use for pain management in patients with rheumatic diseases. Smoked cannabis has not been tested for pain relief in patients suffering from rheumatoid pain (Ko et al., 2016).

\section{Chronic abdominal pain}

In a randomized, double-blind, placebo-controlled paralleldesign phase 2 study (65 participants), no difference between a THC tablet and a placebo tablet in reducing pain measures in patients with chronic abdominal pain due to surgery or chronic pancreatitis was found (de Vries et al., 2017).

\section{Chronic Cancer Pain}

Cancer pain is a chronic pain, often complex, consisting of nociceptive, inflammatory and neuropathic components. Severe and persistent cancer pain is often refractory to treatment with opioid analgesics (Abrams and Guzman, 2015).

Nabiximols has been considerably studied in patients with cancer pain. It has been conditionally approved in Canada and some European countries for the treatment of cancerrelated pain. Currently, it is in phase 3 trials for cancer pain. A multicenter, double-blind, randomized, placebo-controlled study (177 patients) demonstrated that nabiximols $(2.7 \mathrm{mg}$ $\mathrm{THC}+2.5 \mathrm{mg} \mathrm{CBD}$ ) given for 2 weeks is superior to a placebo for pain relief in advanced cancer patients whose pain was not fully relieved by strong opioids (Johnson et al., 2010). A randomized, placebo-controlled, graded-dose trial with advanced cancer patients (88-91 per group) whose pain was not fully relieved by strong opioids, demonstrated significantly better pain relief and sleep with THC:CBD oromucosal spray following 35 days of treatment with lower doses (1-4 and 610 sprays/day), compared with placebo (Portenoy et al., 2012). In an open-label extension study of 43 patients with longterm use of the THC:CBD oromucosal spray there was no need for increasing the dose of the spray or the dose of other analgesics (Johnson et al., 2013). However, results of more recent studies differ from previous ones and are not promising for the use of nabiximols in the treatment of cancer pain. Namely, two studies (multicenter, randomized, doubleblind, placebo-controlled, and parallel-group) conducted by GW Pharmaceuticals, the manufacturer of nabiximols, suggested that the effects of nabiximols in patients with cancer pain resistant to opioid analgesics were not different from placebo (Fallon et al., 2017). In fact, it was shown that nabiximols is superior to placebo in a patient sub-population studied in the United States, but not in sub-populations studied outside of United States, and this finding warrants further examination.

At present, there is insufficient evidence to support the approval of dronabinol and nabilone for the treatment of any type of pain, including cancer pain. In an observational study of patients with advanced cancer, nabilone improved management of pain, nausea, anxiety and distress when compared with untreated patients. Nabilone was also associated with a decreased use of opioids and other pain killers, as well as dexamethasone, metoclopramide, and ondansetron (Maida et al., 2008). Two studies examined the effects of dronabinol on cancer pain. In the first, randomized, double-blind, placebo-controlled, doseranging study involving ten patients, significant pain relief was obtained with 15- and 20-mg doses; however, a 20-mg dose induced somnolence (Noyes et al., 1975b). In a follow-up, single-dose study involving 36 patients, doses of 10 and $20 \mathrm{mg}$ 
of dronabinol produced analgesic effects that were equivalent to doses of 60 and $120 \mathrm{mg}$ of codeine, respectively (Noyes et al., 1975a). However, higher doses of dronabinol were found to be more sedating than codeine. It can be concluded that the effectiveness of cannabinoids in the treatment of chronic cancer pain is questionable. However, whether cannabinoids show some other improvements in cancer patients (sleep, quality of life) remains to be explored. More research is required to establish the role of cannabinoids in the treatment of cancer pain.

There are some case studies, but no published controlled clinical trials, on the use of inhaled cannabis for the treatment of pain in patients with cancer. Also, inhaled cannabis could be effective against chemotherapy-induced neuropathic pain in patients with cancer (Wilsey et al., 2013; Wilsey et al., 2016).

\section{Tolerability and Safety of Cannabis/Cannabinoids in the Treatment of Chronic Pain \\ Short-Term Tolerability and Safety}

Findings from available short-term clinical studies suggest that the safety profile of the short-term use (days to weeks) of cannabis/cannabinoids for pain treatment is acceptable. Their short-term use was associated with an increased risk of adverse events, but they were mostly mild and well tolerated (Wang et al., 2008; Lynch and Campbell, 2011; Andreae et al., 2015; Lynch and Ware, 2015; Whiting et al., 2015; Meng et al., 2017). The psychoactive effects of inhaled cannabis were dosedependent, rare and mild in intensity (Andreae et al., 2015). The treatment with oral cannabinoids was associated with limited tolerability. They produce more cannabinoid-related side effects than placebo, but the side effects are mild to moderate and short-lived (Meng et al., 2017).

One systematic review of safety studies (23 RCTs and 8 observational studies) of medical cannabis and cannabinoids found that short-term use appeared to increase the risk of nonserious adverse events and that they represent $96.6 \%$ of all reported adverse events (Wang et al., 2008). Usually no difference in the incidence rate of serious adverse events was found between the group of patients assigned medical cannabis/cannabinoids and the control group. Psychiatric adverse effects are the most common reason for withdrawal of the treatment. The most commonly reported adverse effect was dizziness (15.5\%), followed by drowsiness, faintness, fatigue, headache, problems with memory and concentration, the ability to think and make decisions, sensory changes, including lack of balance and slower reaction times (increased motor vehicle accidents), nausea, dry mouth, tachycardia, hypertension, conjunctival injection, muscle relaxation, etc. (Wang et al., 2008; Belendiuk et al., 2015). Tolerance to these adverse effects develops soon after the beginning of treatment. Cannabis/cannabinoids can cause mood changes or a feeling of euphoria, dysphoria, anxiety and even hallucinations and paranoia. They can also worsen depression, mania or other mental illnesses. Due to lack of cannabinoid receptors in the brainstem areas controlling respiration, lethal overdoses from cannabis do not occur.

\section{Long-Term Tolerability and Safety}

As cannabis/cannabinoids are intended for treating chronic pain conditions, their long-term tolerability and safety has to be precisely determined, as do the potential health effects of recreational cannabis use (Mattick, 2016). The brain develops a tolerance to cannabinoids, and long-term studies with cannabinoids need to answer the question whether pain can be constantly controlled with these drugs, or whether tolerance and a hyperalgesic response can occur. However, at present there are few well-designed clinical trials and observational studies for long-term medicinal cannabis use that have examined tolerability and safety (mostly in MS patients and in use of oral cannabinoids).

One controlled (open-label) study has evaluated the safety and tolerability of cannabis (a standardized botanical cannabis product that contains $12.5 \%$ tetrahydrocannabinol) used for 1 year in 215 patients (from seven clinics across Canada) with chronic non-cancer pain (Ware et al., 2015). There was a higher rate of adverse events (mostly mild to moderate with respect to the nervous system and psychiatric disorders) among cannabis users when compared to controls, but not for serious adverse events at an average dose of $2.5 \mathrm{~g}$ botanical cannabis per day. The conclusion of the authors of this study is that cannabis is tolerated well and relatively safe when used long-term. The beneficial effect persists over time, indicating that cannabis use for over 1 year does not induce analgesic tolerance.

The effectiveness and long-term safety of cannabinoid capsules (2.5 mg dronabinol vs. cannabis extract containing $2.5 \mathrm{mg}$ THC, $1.25 \mathrm{mg}$ CBD vs. placebo) in MS (630 patient) was studied in a 1-year randomized, double-blind, placebo-controlled trial follow-up of a randomized parent study (Zajicek et al., 2005). The number of patients who withdrew due to side effects was similar between groups. Also, serious side effects were similar in the placebo and active groups and were related to the medical condition. Generally, there were no safety concerns reported in this study.

The safety and tolerability of nabiximols long-term use in different conditions (cancer pain, spasticity and neuropathic pain in MS patients) has been studied in a series of trials of up to 2 years duration (Wade et al., 2006; Rog et al., 2007; Johnson et al., 2013; Serpell et al., 2013). All were uncontrolled, openlabel extension trials. Adverse events and serious adverse events were cannabinoid-related with no safety concerns reported. Also, there was no evidence for a loss of effect in the relief of pain with long-term use.

Taking into account all long-term safety studies, cannabis appears to be better tolerated than oral cannabinoids (RomeroSandoval et al., 2017). This interpretation is based on a single study with cannabis (Ware et al., 2015) and should therefore be taken with caution.

Long-term adverse effects of medical cannabis are difficult to evaluate. They mainly come from studies with recreational cannabis use (Mattick, 2016). However, there are many differences between medical cannabis and recreational cannabis 
users as regards the amounts used, the existence of comorbidities, the mode of drug delivery (Wang et al., 2008), etc. Thus, the adverse effects of recreational cannabis use cannot be directly extrapolated to medical cannabis use. The safety of medical and recreational cannabis should be evaluated separately. There is evidence that long-term cannabis use is associated with an increased risk of addiction, cognitive impairment, altered brain development and an increased risk of mental disorders (anxiety, depression, and psychotic illness) with adolescent use, and adverse physical health effects such as cardiovascular disease, chronic obstructive pulmonary disease and lung cancer (Volkow et al., 2014; Mattick, 2016). It is well established and documented that CBD may lower the risk for developing psychotic illness that is related to cannabis use (Iseger and Bossong, 2015).

Cannabis-use disorders (CUD) are defined in the Diagnostic and Statistical Manual of Mental Disorders (Hasin et al., 2013) and in the International Statistical Classification of Diseases and Related Health Problems (ICD-11). It was estimated that 9\% of those who use cannabis develop CUD (Budney et al., 2007). Risk factors (e.g., cannabis use at an earlier age, frequent use, combined use of abused drugs) for the progression of cannabis use to problem cannabis use (CUD, dependence, and abuse) (NASEM, 2017; Hasin, 2018) are more common among recreative than among medical cannabis users. CUD are associated with psychiatric comorbidities. About one half of patients treated for CUD develop withdrawal symptoms such as dysphoria (anxiety, irritability, depression, and restlessness), insomnia, hot flashes and rarely gastrointestinal symptoms. These symptoms are mild when compared with withdrawal symptoms associated with opioid use. Most of the symptoms appear during the 1st week of cannabis withdrawal and resolve after a few weeks (Gordon et al., 2013; Volkow et al., 2014).

A number of studies have yielded conflicting evidence regarding the risks of various cancers associated with cannabis smoking (Health Canada, 2013). Recently, NASEM (2017) has stated, with a moderate level of evidence, that there is no statistical association between cannabis smoking and lung cancer incidence.

Before grant approval, drug agencies need to be sure that the benefits of medicine outweigh the risks. As the benefits and risks of medical cannabis have not been thoroughly examined, individual products containing cannabinoids have not been approved for the treatment of pain (Ko et al., 2016). Nonetheless, a number of chronic-pain patients use cannabis/cannabinoids for pain relief. Some replaced partially or completely the use of opioids with cannabis/cannabinoids (Boehnke et al., 2016; Lucas and Walsh, 2017; Lucas, 2017; Piper et al., 2017), and others continued to use prescription opioids. Observational studies have found that state legalization of cannabis is associated with a decrease in opioid addiction and opioid-related over-dose deaths (Hayes and Brown, 2014; Powell et al., 2018). Previous studies suggested that the analgesic effects of cannabis are comparable to those of traditional pain medications (Wilsey et al., 2013). However, data on the comparative efficacy and safety of cannabis/cannabinoids versus existing pain treatments, including opioids, are missing. Also, more studies are needed on potentially beneficial or problematic combinations of cannabis/cannabinoids and available analgesics. Further research is expected to provide an answer to the question whether cannabis/cannabinoids can be an effective and safe substitute for opioid therapy in the treatment of chronic pain (Nielsen et al., 2017). New high-quality, long-term exposure trials are required to determine the efficacy and safety of longterm use of medicinal cannabis in the treatment of pain (Hill et al., 2017; Piomelli et al., 2017; Romero-Sandoval et al., 2017). The design of trials should be improved to ensure that they are blinded, placebo-controlled with active comparator, with consistency of pain diagnosis, long-enough duration of treatment, evaluation of the dose-response, homogeneity of the patient population and inclusion of quality of life as an outcome measure (Ko et al., 2016; NASEM, 2017; Piomelli et al., 2017).

Current research evidence supports the use of medical cannabis in the management of chronic pain in adults (NASEM, 2017). As its use in the treatment of chronic pain increases, additional research to support or refute the current evidence base is crucial to provide answers to questions concerning the risk-benefit ratio for medical cannabis use in pain treatment. The implementation of monitoring programs is mandatory and provides an opportunity to accumulate data on the safety and effectiveness of long-term use of medical cannabis in the real world (Hill et al., 2017; Romero-Sandoval et al., 2017). This is important for evidence-based policy making and implementation (Nosyk and Wood, 2012).

\section{SUMMARY}

The key findings are summarized below:

Cannabinoids and cannabis are old drugs but now they are a promising new therapeutic strategy for pain treatment.

Cannabinoids (plant-derived, synthetic) themselves or endocannabinoid-directed therapeutic strategies have been shown to be effective in different animal models of pain (acute nociceptive, neuropathic, inflammatory). However, medical cannabis is not equally effective against all types of pain in humans.

A recent meta-analysis of clinical trials of medical cannabis for chronic pain found substantial evidence encouraging its use in pharmacotherapy of chronic pain. Also, it was shown that medical cannabis may only moderately reduce chronic pain, similar all other currently available analgesic drugs. However, controlled comparative studies on the efficacy and safety of cannabis/cannabinoids and other analgesics, including opioids, are missing.

Inhaled (smoked or vaporized) cannabis is constantly effective in reducing neuropathic pain and this effect is dose-related and can be achieved with a concentration of cannabis THC lower than $10 \%$. Compared to oral cannabinoids, the effect of inhaled cannabis is more rapid, predictable and can be titrated. Compared to inhaled cannabis, the effectiveness of oral cannabinoids in reducing the sensory component of neuropathic pain seems to be less convincing and oral cannabinoids in general may be less tolerable. However, data suggest that they may 
improve secondary measures such as sleep, quality of life and patient satisfaction.

There are no controlled clinical trials on the use of inhaled cannabis for the treatment of cancer or rheumatic (osteoarthritis, rheumatoid arthritis, and fibromyalgia) pain.

Whether oral cannabinoids reduce the intensity of chronic cancer pain is not completely clear. Recent long-term studies of nabiximols are not encouraging.

Sparse literature data show that oral cannabinoids have inadequate efficacy in rheumatological pain conditions. Also, oral cannabinoids do not reduce acute postoperative or chronic abdominal pain.

In general, the efficacy of medical cannabis in pain treatment is not completely clear due to several limitations. Clinical trials are scarce and most were of short duration, with relatively small sample sizes, heterogeneous patient populations, different types of cannabinoids, a range of dosages, variability in the assessment of domains of pain (sensory, affective) and modest effect sizes. Therefore, further larger studies examining specific cannabinoids and strains of cannabis, using improved and objective pain measurements, appropriate dosages and duration of treatment in homogeneous patient populations need to be carried out.

The current review of evidence from clinical trials of medicinal cannabis suggests that the adverse effects of its short-term use are modest, most of them are not serious and are selflimiting.

\section{REFERENCES}

Abrams, D. I., Couey, P., Shade, S. B., Kelly, M. E., and Benowitz, N. (2011). Cannabinoid-opioid interaction in chronic pain. Clin. Pharmacol. Ther. 90, 844-851. doi: 10.1038/clpt.2011.188

Abrams, D. I., and Guzman, M. (2015). Cannabis in cancer care. Clin. Pharmacol. Ther. 97, 575-586. doi: 10.1002/cpt.108

Adamson Barnes, N. S., Mitchell, V. A., Kazantzis, N. P., and Vaughan, C. W. (2016). Actions of the dual FAAH/MAGL inhibitor JZL195 in a murine neuropathic pain model. Br. J. Pharmacol. 173, 77-87. doi: 10.1111/bph.13337

Agurell, S., Halldin, M., Lindgren, J. E., Ohlsson, A., Widman, M., Gillespie, H., et al. (1986). Pharmacokinetics and metabolism of delta 1-tetrahydrocannabinol and other cannabinoids with emphasis on man. Pharmacol. Rev. 38, 21-43.

Ahn, K., Smith, S. E., Liimatta, M. B., Beidler, D., Sadagopan, N., Dudley, D. T., et al. (2011). Mechanistic and pharmacological characterization of PF-04457845: a highly potent and selective fatty acid amide hydrolase inhibitor that reduces inflammatory and noninflammatory pain. J. Pharmacol. Exp. Ther. 338, 114124. doi: 10.1124/jpet.111.180257

Ahrens, J., Demir, R., Leuwer, M., de la Roche, J., Krampfl, K., Foadi, N., et al. (2009). The nonpsychotropic cannabinoid cannabidiol modulates and directly activates alpha-1 and alpha-1-Beta glycine receptor function. Pharmacology 83, 217-222. doi: 10.1159/000201556

Aiello, F., Carullo, G., Badolato, M., and Brizzi, A. (2016). TRPV1-FAAH-COX: the couples game in pain treatment. Chem. Med. Chem. 11, 1686-1694. doi: 10.1002/cmdc.201600111

Anand, P., Whiteside, G., Fowler, C. J., and Hohmann, A. G. (2009). Targeting $\mathrm{CB}_{2}$ receptors and the endocannabinoid system for the treatment of pain. Brain Res. Rev. 60, 255-266. doi: 10.1016/j.brainresrev.2008.12.003

Andre, C. M., Hausman, J. F., and Guerriero, G. (2016). Cannabis sativa: the plant of the thousand and one molecules. Front. Plant Sci. 7:19. doi: 10.3389/fpls.2016. 00019

Andreae, M. H., Carter, G. M., Shaparin, N., Suslov, K., Ellis, R. J., Warem, M. A., et al. (2015). Inhaled cannabis for chronic neuropathic pain: a meta-analysis
Long-term safety assessment of medicinal cannabis is based on scant clinical trials, so the evidence is limited, and the safety interpretation should be taken cautiously. More research is needed to evaluate the adverse effects of long-term use of medical cannabis.

In view of the limited effect size and the low but not unimportant risk of serious, adverse events, a more precise determination of the risk-to-benefit ratio for medicinal cannabis in pain treatment is needed to help establishing evidence-based policy implementation.

Current evidence supports the use of medical cannabis in the treatment of chronic pain in adults. Monitoring and follow-up of patients is obligatory.

\section{AUTHOR CONTRIBUTIONS}

SV conceived and wrote manuscript. DS participated in literature search. All authors revised the manuscript and approved the final manuscript for submission.

\section{FUNDING}

This work was supported by the Ministry of Education, Science and Technological Development of Republic Serbia (Grant 175023).

of individual patient data. J. Pain 16, 1221-1232. doi: 10.1016/j.jpain.2015. 07.009

Attal, N., Cruccu, G., Baron, R., Haanpää, M., Hansson, P., Jensen, T. S., et al. (2010). EFNS guidelines on the pharmacological treatment of neuropathic pain: 2010 revision. Eur. J. Neurol. 17:1113-e88. doi: 10.1111/j.1468-1331.2010. 02999.x

Atwood, B. K., and Mackie, K. (2010). $\mathrm{CB}_{2}$ : a cannabinoid receptor with an identity crisis. Br. J. Pharmacol. 160, 467-479. doi: 10.1111/j.1476-5381.2010.00729.x

Atwood, B. K., Wager-Miller, J., Haskins, C., Straiker, A., and Mackie, K. (2012). Functional selectivity in $\mathrm{CB}_{2}$ cannabinoid receptor signaling and regulation: implications for the therapeutic potential of $\mathrm{CB}_{2}$ ligands. Mol. Pharmacol. 81, 250-263. doi: 10.1124/mol.111.074013

Bair, M. J., and Sanderson, T. R. (2011). Coanalgesics for chronic pain therapy: a narrative review. Postgrad. Med. 123, 140-150. doi: 10.3810/pgm.2011.11.2504

Bakas, T., van Nieuwenhuijzen, P. S., Devenish, S. O., McGregor, I. S., Arnold, J. C., and Chebib, M. (2017). The direct actions of cannabidiol and 2-arachidonoyl glycerol at GABA(A) receptors. Pharmacol. Res. 119, 358-370. doi: 10.1016/j. phrs.2017.02.022

Barann, M., Molderings, G., Brüss, M., Bönisch, H., Urban, B. W., and Göthert, M. (2002). Direct inhibition by cannabinoids of human 5-HT3A receptors: probable involvement of an allosteric modulatory site. Br. J. Pharmacol. 137, 589-596. doi: 10.1038/sj.bjp.0704829

Beaulieu, P. (2006). Effects of nabilone, a synthetic cannabinoid, on postoperative pain. Can. J. Anaesth. 53, 769-775. doi: 10.1007/BF03022793

Belendiuk, K. A., Baldini, L. L., and Bonn-Miller, M. O. (2015). Narrative review of the safety and efficacy of marijuana for the treatment of commonly stateapproved medical and psychiatric disorders. Addict. Sci. Clin. Pract. 10:10. doi: 10.1186/s13722-015-0032-7

Bertolini, A., Ferrari, A., Ottani, A., Guerzoni, S., Tacchi, R., and Leone, S. (2006). Paracetamol: new vistas of an old drug. CNS Drug Rev. 12, 250-275. doi: 10. 1111/j.1527-3458.2006.00250.x

Boehnke, K. F., Litinas, E., and Clauw, D. J. (2016). Medical cannabis use is associated with decreased opiate medication use in a retrospective 
cross-sectional survey of patients with chronic pain. J. Pain 17, 739-744. doi: 10.1016/j.jpain.2016.03.002

Booker, L., Kinsey, S. G., Abdullah, R. A., Blankman, J. L., Long, J. Z., Ezzili, C., et al. (2012). The fatty acid amide hydrolase (FAAH) inhibitor PF-3845 acts in the nervous system to reverse LPS-induced tactile allodynia in mice. $\mathrm{Br}$. J. Pharmacol. 165, 2485-2496. doi: 10.1111/j.1476-5381.2011.01445

Boychuk, D. G., Goddard, G., Mauro, G., and Orellana, M. F. (2015). The effectiveness of cannabinoids in the management of chronic nonmalignant neuropathic pain: a systematic review. J. Oral Facial Pain Headache 29, 7-14. doi: $10.11607 /$ ofph. 1274

Budney, A. J., Roffman, R., Stephens, R. S., and Walker, D. (2007). Marijuana dependence and its treatment. Addict. Sci. Clin. Pract. 4, 4-16. doi: 10.1151/ ASCP07414

Buggy, D. J., Toogood, L., Maric, S., Sharpe, P., Lambert, D. G., and Rowbotham, D. J. (2003). Lack of analgesic efficacy of oral delta-9-tetrahydrocannabinol in postoperative pain. Pain 106, 169-172. doi: 10.1016/S0304-3959(03)00331-2

Burgos, E., Pascual, D., Martín, M. I., and Goicoechea, C. (2010). Antinociceptive effect of the cannabinoid agonist, WIN 55,212-2, in the orofacial and temporomandibular formalin tests. Eur. J. Pain 14, 40-48. doi: 10.1016/j.ejpain. 2009.02.003

Burstein, S. (2015). Cannabidiol (CBD) and its analogs: a review of their effects on inflammation. Bioorg. Med. Chem. 23, 1377-1385. doi: 10.1016/j.bmc.2015.01. 059

Canadian Agency for Drugs and Technologies in Health (2016). Cannabinoid Buccal Spray for Chronic Non-Cancer or Neuropathic Pain: A Review of Clinical Effectiveness, Safety, and Guidelines [Internet]. Ottawa: Canadian Agency for Drugs and Technologies in Health.

Caprioli, A., Coccurello, R., Rapino, C., Di Serio, S., Di Tommaso, M., Vertechy, M., et al. (2012). The novel reversible fatty acid amide hydrolase inhibitor ST4070 increases endocannabinoid brain levels and counteracts neuropathic pain in different animal models. J. Pharmacol. Exp. Ther. 342, 188-195. doi: 10.1124/jpet.111.191403

Carey, L. M., Slivicki, R. A., Leishman, E., Cornett, B., Mackie, K., Bradshaw, H., et al. (2016). A pro-nociceptive phenotype unmasked in mice lacking fatty-acid amide hydrolase. Mol. Pain 12:1744806916649192. doi: 10.1177/ 1744806916649192

Carter, G. T., Weydt, P., Kyashna-Tocha, M., and Abrams, D. I. (2004). Medicinal cannabis: rational guidelines for dosing. IDrugs 7, 464-470.

Chanda, P. K., Gao, Y., Mark, L., Btesh, J., Strassle, B. W., Lu, P., et al. (2010). Monoacylglycerol lipase activity is a critical modulator of the tone and integrity of the endocannabinoid system. Mol. Pharmacol. 78, 996-1003. doi: 10.1124/ mol.110.068304

Chemin, J., Monteil, A., Perez-Reyes, E., Nargeot, J., and Lory, P. (2001). Direct inhibition of T-type calcium channels by the endogenous cannabinoid anandamide. EMBO J. 20, 7033-7040. doi: 10.1093/emboj/20.24.7033

Clapper, J. R., Moreno-Sanz, G., Russo, R., Guijarro, A., Vacondio, F., Duranti, A., et al. (2010). Anandamide suppresses pain initiation through a peripheral endocannabinoid mechanism. Nat. Neurosci. 13, 1265-1270. doi: 10.1038/nn. 2632

Clayton, N., Marshall, F. H., Bountra, C., and O'Shaughnessy, C. T. (2002). CB 1 and $\mathrm{CB}_{2}$ cannabinoid receptors are implicated in inflammatory pain. Pain 96 , 253-260. doi: 10.1016/S0304-3959(01)00454-7

Comelli, F., Giagnoni, G., Bettoni, I., Colleoni, M., and Costa, B. (2008). Antihyperalgesic effect of a Cannabis sativa extract in a rat model of neuropathic pain: mechanisms involved. Phytother. Res. 22, 1017-1024. doi: 10.1002/ptr.2401

Costa, B., Trovato, A. E., Comelli, F., Giagnoni, G., and Colleoni, M. (2007). The non-psychoactive cannabis constituent cannabidiol is an orally effective therapeutic agent in rat chronic inflammatory and neuropathic pain. Eur. J. Pharmacol. 556, 75-83. doi: 10.1016/j.ejphar.2006.11.006

Cristino, L., de Petrocellis, L., Pryce, G., Baker, D., Guglielmotti, V., and Di Marzo, V. (2006). Immunohistochemical localization of cannabinoid type 1 and vanilloid transient receptor potential vanilloid type 1 receptors in the mouse brain. Neuroscience 139, 1405-1415. doi: 10.1016/j.neuroscience.2006.02.074

De Petrocellis, L., Ligresti, A., Moriello, A. S., Allarà, M., Bisogno, T., Petrosino, S., et al. (2011). Effects of cannabinoids and cannabinoid-enriched Cannabis extracts on TRP channels and endocannabinoid metabolic enzymes. Br. J. Pharmacol. 163, 1479-1494. doi: 10.1111/j.1476-5381.2010.01166.x de Vries, M., van Rijckevorsel, D. C. M., Vissers, K. C. P., Wilder-Smith, O. H. G., and van Goor, H. (2017). Pain and nociception neuroscience research group. tetrahydrocannabinol does not reduce pain in patients with chronic abdominal pain in a phase 2 placebo-controlled study. Clin. Gastroenterol. Hepatol. 15, 1079-1086. doi: 10.1016/j.cgh.2016.09.147

Deng, L., Guindon, J., Cornett, B. L., Makriyannis, A., Mackie, K., and Hohmann, A. G. (2015). Chronic cannabinoid receptor 2 activation reverses paclitaxel neuropathy without tolerance or cannabinoid receptor 1-dependent withdrawal. Biol. Psychiatry 77, 475-487. doi: 10.1016/j.biopsych.2014.04.009

Dhopeshwarkar, A., and Mackie, K. (2014). $\mathrm{CB}_{2}$ Cannabinoid receptors as a therapeutic target-what does the future hold? Mol. Pharmacol. 86, 430-437. doi: $10.1124 / \mathrm{mol} .114 .094649$

Elmes, S. J., Jhaveri, M. D., Smart, D., Kendall, D. A., and Chapman, V. (2004). Cannabinoid $\mathrm{CB}_{2}$ receptor activation inhibits mechanically evoked responses of wide dynamic range dorsal horn neurons in naïve rats and in rat models of inflammatory and neuropathic pain. Eur. J. Neurosci. 20, 2311-2320. doi: 10.1111/j.1460-9568.2004.03690.x

Elmes, S. J., Winyard, L. A., Medhurst, S. J., Clayton, N. M., Wilson, A. W., Kendall, D. A., et al. (2005). Activation of $\mathrm{CB}_{1}$ and $\mathrm{CB}_{2}$ receptors attenuates the induction and maintenance of inflammatory pain in the rat. Pain 118, 327-335. doi: 10.1016/j.pain.2005.09.005

ElSohly, M. A., Radwan, M. M., Gul, W., Chandra, S., and Galal, A. (2017). Phytochemistry of Cannabis sativa L. Prog. Chem. Org. Nat. Prod. 103, 1-36. doi: 10.1007/978-3-319-45541-9_1

Facci, L., Dal Toso, R., Romanello, S., Buriani, A., Skaper, S. D., and Leon, A. (1995). Mast cells express a peripheral cannabinoid receptor with differential sensitivity to anandamide and palmitoylethanolamide. Proc. Natl. Acad. Sci. U.S.A. 92, 3376-3380. doi: 10.1073/pnas.92.8.3376

Fallon, M. T., Albert Lux, E., McQuade, R., Rossetti, S., Sanchez, R., and Sun, W. (2017). Sativex oromucosal spray as adjunctive therapy in advanced cancer patients with chronic pain unalleviated by optimized opioid therapy: two double-blind, randomized, placebo-controlled phase 3 studies. Br. J. Pain 11, 119-133. doi: 10.1177/2049463717710042

Fichna, J., Sałaga, M., Stuart, J., Saur, D., Sobczak, M., and Zatorski, H. (2014). Selective inhibition of FAAH produces antidiarrheal and antinociceptive effect mediated by endocannabinoids and cannabinoid-like fatty acid amides. Neurogastroenterol. Motil. 26, 470-481. doi: 10.1111/nmo. 12272

Finnerup, N. B., Attal, N., Haroutounian, S., McNicol, E., Baron, R., Dworkin, R. H., et al. (2015). Pharmacotherapy for neuropathic pain in adults: systematic review, meta-analysis and updated NeuPSIG recommendations. Lancet Neurol. 14, 162-173. doi: 10.1016/S1474-4422(14)70251-0

Fitzcharles, M. A., Baerwald, C., Ablin, J., and Häuser, W. (2016). Efficacy, tolerability and safety of cannabinoids in chronic pain associated with rheumatic diseases (fibromyalgia syndrome, back pain, osteoarthritis, rheumatoid arthritis): a systematic review of randomized controlled trials. Schmerz 30, 47-61. doi: 10.1007/s00482-015-0084-3

Fox, A., Kesingland, A., Gentry, C., McNair, K., Patel, S., Urban, L., et al. (2001). The role of central and peripheral cannabinoid 1 receptors in the antihyperalgesic activity of cannabinoids in a model of neuropathic pain. Pain 92, 91-100. doi: 10.1016/S0304-3959(00)00474-7

Fukuda, S., Kohsaka, H., Takayasu, A., Yokoyama, W., Miyabe, C., Miyabe, Y., et al. (2014). Cannabinoid receptor 2 as a potential therapeutic target in rheumatoid arthritis. BMC Musculoskelet. Disord. 15:275. doi: 10.1186/1471-2474-15-275

Gatchel, R. J., McGeary, D. D., McGeary, C. A., and Lippe, B. (2014). Interdisciplinary chronic pain management: past, present, and future. Am. Psychol. 69, 119-130. doi: 10.1037/a0035514

Gewandter, J. S., Dworkin, R. H., Turk, D. C., McDermott, M. P., Baron, R., Gastonguay, M. R., et al. (2014). Research designs for proof-of-concept chronic pain clinical trials: IMMPACT recommendations. Pain 155, 1683-1695. doi: 10.1016/j.pain.2014.05.025

Giordano, C., Cristino, L., Luongo, L., Siniscalco, D., Petrosino, S., Piscitelli, F., et al. (2012). TRPV1-dependent and -independent alterations in the limbic cortex of neuropathic mice: impact on glial caspases and pain perception. Cereb. Cortex 22, 2495-2518. doi: 10.1093/cercor/bhr328

Gordon, A. J., Conley, J. W., and Gordon, J. M. (2013). Medical consequences of marijuana use: a review of current literature. Curr. Psychiatry Rep. 15:419. doi: 10.1007/s11920-013-0419-7 
Grim, T. W., Ghosh, S., Hsu, K. L., Cravatt, B. F., Kinsey, S. G., and Lichtman, A. H. (2014). Combined inhibition of FAAH and COX produces enhanced anti-allodynic effects in mouse neuropathic and inflammatory pain models. Pharmacol. Biochem. Behav. 124, 405-411. doi: 10.1016/j.pbb.2014.07.008

Grotenhermen, F. (2003). Pharmacokinetics and pharmacodynamics of cannabinoids. Clin. Pharmacokinet. 42, 327-360. doi: 10.2165/00003088200342040-00003

Guerrero, A. V., Quang, P., Dekker, N., Jordan, R. C., and Schmidt, B. L. (2008). Peripheral cannabinoids attenuate carcinoma-induced nociception in mice. Neurosci. Lett. 433, 77-81. doi: 10.1016/j.neulet.2007.12.053

Gui, H., Liu, X., Liu, L. R., Su, D. F., and Dai, S. M. (2015). Activation of cannabinoid receptor 2 attenuates synovitis and joint distruction in collageninduced arthritis. Immunobiology 220, 817-822. doi: 10.1016/j.imbio.2014.12. 012

Hasin, D. S. (2018). US epidemiology of cannabis use and associated problems. Neuropsychopharmacology 43, 195-212. doi: 10.1038/npp.2017.198

Hasin, D. S., O’Brien, C. P., Auriacombe, M., Borges, G., Bucholz, K., Budney, A., et al. (2013). DSM-5 criteria for substance use disorders: recommendations and rationale. Am. J. Psychiatry 170, 834-851. doi: 10.1176/appi.ajp.2013.12060782

Hayes, M. J., and Brown, M. S. (2014). Legalization of medical marijuana and incidence of opioid mortality. JAMA Intern. Med. 174, 1673-1674. doi: 10.1001/ jamainternmed.2014.2716

Health Canada (2013). Cannabis (Marihuana, Marijuana) and the Cannabinoids. Dried Plant for Administration by Ingestion or other Means. Psychoactive Agent. Information for Health Care Professionals: Cannabis (Marihuana, Marijuana) and the Cannabinoids. Available at: https://www.canada.ca/en/health-canada/services/drugs-health-products/ medical-use-marijuana/information-medical-practitioners/informationhealth-care-professionals-cannabis-marihuana-marijuana-cannabinoids.html

Hejazi, N., Zhou, C., Oz, M., Sun, H., Ye, J. H., and Zhang, L. (2006). Delta9tetrahydrocannabinol and endogenous cannabinoid anandamide directly potentiate the function of glycine receptors. Mol. Pharmacol. 69, 991-997.

Herzberg, U., Eliav, E., Bennett, G. J., and Kopin, I. J. (1997). The analgesic effects of $\mathrm{R}^{+}$-WIN 55,212-2 mesylate, a high affinity cannabinoid agonist, in a rat model of neuropathic pain. Neurosci. Lett. 221, 157-160. doi: 10.1016/S0304-3940(96) 13308-5

Hill, K. P., Palastro, M. D., Johnson, B., and Ditre, J. W. (2017). Cannabis and pain: a clinical review. Cannabis Cannabinoid Res. 2, 96-104. doi: 10.1089/can.2017. 0017

Holdcroft, A., Maze, M., Doré, C., Tebbs, S., and Thompson, S. (2006). A multicenter dose-escalation study of the analgesic and adverse effects of an oral cannabis extract (Cannador) for postoperative pain management. Anesthesiology 104, 1040-1046. doi: 10.1097/00000542-200605000-00021

Horvath, G., Kekesi, G., Nagy, E., and Benedek, G. (2008). The role of TRPV1 receptors in the antinociceptive effect of anandamide at spinal level. Pain 134, 277-284. doi: 10.1016/j.pain.2007.04.032

Howard, P., Twycross, R., Shuster, J., Mihalyo, M., and Wilcock, A. (2013). Cannabinoids. J. Pain Symptom Manage. 46, 142-149. doi: 10.1016/j. jpainsymman.2013.05.002

Hsieh, G. C., Pai, M., Chandran, P., Hooker, B. A., Zhum, C. Z., Salyers, A. K., et al. (2011). Central and peripheral sites of action for CB2 receptor mediated analgesic activity in chronic inflammatory and neuropathic pain models in rats. Br. J. Pharmacol. 162, 428-440. doi: 10.1111/j.1476-5381.2010. 01046.x

Huang, S. M., Bisogno, T., Petros, T. J., Chang, S. Y., Zavitsanos, P. A., Zipkin, R. E., et al. (2001). Identification of a new class of molecules, the arachidonyl amino acids, and characterization of one member that inhibits pain. J. Biol. Chem. 276, 42639-42644. doi: 10.1074/jbc.M107351200

Huestis, M. A. (2007). Human cannabinoid pharmacokinetics. Chem. Biodivers. 4, 1770-1804. doi: 10.1002/cbdv.200790152

Huggins, J. P., Smart, T. S., Langman, S., Taylor, L., and Young, T. (2012). An efficient randomised, placebo-controlled clinical trial with the irreversible fatty acid amide hydrolase-1 inhibitor PF-04457845, which modulates endocannabinoids but fails to induce effective analgesia in patients with pain due to osteoarthritis of the knee. Pain 153, 1837-1846. doi: 10.1016/j.pain.2012. 04.020

Hwang, J., Adamson, C., Butler, D., Janero, D. R., Makriyannis, A., and Bahr, B. A. (2010). Enhancement of endocannabinoid signaling by fatty acid amide hydrolase inhibition: a neuroprotective therapeutic modality. Life Sci. 86, 615623. doi: 10.1016/j.lfs.2009.06.003

Ibrahim, M. M., Porreca, F., Lai, J., Albrecht, P. J., Rice, F. L., Khodorova, A., et al. (2005). $\mathrm{CB}_{2}$ cannabinoid receptor activation produces antinociception by stimulating peripheral release of endogenous opioids. Proc. Natl. Acad. Sci. U.S.A. 102, 3093-3098. doi: 10.1073/pnas.040988 8102

Ibsen, M. S., Connor, M., and Glass, M. (2017). Cannabinoid $\mathrm{CB}_{1}$ and $\mathrm{CB}_{2}$ receptor signaling and bias. Cannabis Cannabinoid Res. 2, 48-60. doi: 10.1089/can.2016. 0037

Ignatowska-Jankowska, B. M., Ghosh, S., Crowe, M. S., Kinsey, S. G., Niphakis, M. J., Abdullah, R. A., et al. (2014). In vivo characterization of the highly selective monoacylglycerol lipase inhibitor KML29: antinociceptive activity without cannabimimetic side effects. Br. J. Pharmacol. 171, 1392-1407. doi: 10.1111/bph. 12298

Iseger, T. A., and Bossong, M. G. (2015). A systematic review of the antipsychotic properties of cannabidiol in humans. Schizophr. Res. 162, 153-161. doi: 10.1016/ j.schres.2015.01.033

Issa, M. A., Narang, S., Jamison, R. N., Michna, E., Edwards, R. R., Penetar, D. M., et al. (2014). The subjective psychoactive effects of oral dronabinol studied in a randomized, controlled crossover clinical trial for pain. Clin. J. Pain 30, 472-478. doi: 10.1097/AJP.0000000000000022

Jawahar, R., Oh, U., Yang, S., and Lapane, K. L. (2013). A systematic review of pharmacological pain management in multiple sclerosis. Drugs 73, 1711-1722. doi: 10.1007/s40265-013-0125-0

Jesse Lo, V., Fu, J., Astarita, G., La Rana, G., Russo, R., Calignano, A., et al. (2005). The nuclear receptor peroxisome proliferator-activated receptoralpha mediates the anti-inflammatory actions of palmitoylethanolamide. Mol. Pharmacol. 67, 15-19. doi: 10.1124/mol.104.006353

Johnson, J. R., Burnell-Nugent, M., Lossignol, D., Ganae-Motan, E. D., Potts, R., and Fallon, M. T. (2010). Multicenter, double-blind, randomized, placebocontrolled, parallel-group study of the efficacy, safety, and tolerability of THC:CBD extract and THC extract in patients with intractable cancer-related pain. J. Pain Symptom Manage. 39, 167-179. doi: 10.1016/j.jpainsymman.2009. 06.008

Johnson, J. R., Lossignol, D., Burnell-Nugent, M., and Fallon, M. T. (2013). An open-label extension study to investigate the long-term safety and tolerability of THC/CBD oromucosal spray and oromucosal THC spray in patients with terminal cancer-related pain refractory to strong opioid analgesics. J. Pain Symptom Manage. 46, 207-218. doi: 10.1016/j.jpainsymman.2012. 07.014

Kaczocha, M., Rebecchi, M. J., Ralph, B. P., Teng, Y. H., Berger, W. T., Galbavy, W., et al. (2014). Inhibition of fatty acid binding proteins elevates brain anandamide levels and produces analgesia. PLoS One 9:e94200. doi: 10.1371/journal.pone. 0094200

Kahan, M., Srivastava, A., Spithoff, S., and Bromley, L. (2014). Prescribing smoked cannabis for chronic noncancer pain: preliminary recommendations. Can. Fam. Physician 60, 1083-1090.

Kano, M. (2014). Control of synaptic function by endocannabinoid-mediated retrograde signaling. Proc. Jpn. Acad. Ser. B Phys. Biol. Sci. 90, 235-250. doi: 10.2183/pjab.90.235

Kaur, R., Sidhu, P., and Singh, S. (2016). What failed BIA 10-2474 Phase I clinical trial? Global speculations and recommendations for future Phase I trials. J. Pharmacol. Pharmacother. 7, 120-126. doi: 10.4103/0976-500X. 189661

Khasabova, I. A., Gielissen, J., Chandiramani, A., Harding-Rose, C., Odeh, D. A., Simone, D. A., et al. (2011). $\mathrm{CB}_{1}$ and $\mathrm{CB}_{2}$ receptor agonists promote analgesia through synergy in a murine model of tumor pain. Behav. Pharmacol. 22, 607-616. doi: 10.1097/FBP.0b013e3283474a6d

Khasabova, I. A., Khasabov, S., Paz, J., Harding-Rose, C., Simone, D. A., and Seybold, V. S. (2012). Cannabinoid type-1 receptor reduces pain and neurotoxicity produced by chemotherapy. J. Neurosci. 32, 7091-7101. doi: 10. 1523/JNEUROSCI.0403-12.2012

Khasabova, I. A., Khasabov, S. G., Harding-Rose, C., Coicou, L. G., Seybold, B. A., Lindberg, A. E., et al. (2008). A decrease in anandamide signaling contributes to the maintenance of cutaneous mechanical hyperalgesia in a model of bone cancer pain. J. Neurosci. 28, 11141-11152. doi: 10.1523/JNEUROSCI.2847-08. 2008 
Khurana, L., Mackie, K., Piomelli, D., and Kendall, D. A. (2017). Modulation of $\mathrm{CB}_{1}$ cannabinoid receptor by allosteric ligands: pharmacology and therapeutic opportunities. Neuropharmacology 124, 3-12. doi: 10.1016/j.neuropharm.2017. 05.018

Kinsey, S. G., Long, J. Z., Cravatt, B. F., and Lichtman, A. H. (2010). Fatty acid amide hydrolase and monoacylglycerol lipase inhibitors produce anti-allodynic effects in mice through distinct cannabinoid receptor mechanisms. J. Pain 11, 1420-1428. doi: 10.1016/j.jpain.2010.04.001

Kinsey, S. G., Mahadevan, A., Zhao, B., Sun, H., Naidu, P. S., Razdan, R. K., et al. (2011). The $\mathrm{CB}_{2}$ cannabinoid receptor-selective agonist O-3223 reduces pain and inflammation without apparent cannabinoid behavioral effects. Neuropharmacology 60, 244-251. doi: 10.1016/j.neuropharm.2010. 09.004

Kiritoshi, T., Ji, G., and Neugebauer, V. (2016). Rescue of impaired mGluR5-driven endocannabinoid signaling restores prefrontal cortical output to inhibit pain in arthritic rats. J. Neurosci. 36, 837-850. doi: 10.1523/JNEUROSCI.4047-15. 2016

Klein, T. W. (2005). Cannabinoid-based drugs as anti-inflammatory therapeutics. Nat. Rev. Immunol. 5, 400-411. doi: 10.1038/nril602

Ko, G. D., Bober, S. L., Mindra, S., and Moreau, J. M. (2016). Medical cannabis the Canadian perspective. J. Pain Res. 9, 735-744. doi: 10.2147/JPR.S98182

Kondrad, E., and Reid, A. (2013). Colorado family physicians' attitudes toward medical marijuana. J. Am. Board. Fam. Med. 26, 52-60. doi: 10.3122/jabfm. 2013.01.120089

Kraft, B., Frickey, N. A., Kaufmann, R. M., Reif, M., Frey, R., Gustorff, B., et al. (2008). Lack of analgesia by oral standardized cannabis extract on acute inflammatory pain and hyperalgesia in volunteers. Anesthesiology 109, 101-110. doi: 10.1097/ALN.0b013e31817881e1

La Porta, C., Bura, S. A., Llorente-Onaindia, J., Pastor, A., Navarrete, F., GarcíaGutiérrez, M. S., et al. (2015). Role of the endocannabinoid system in the emotional manifestations of osteoarthritis pain. Pain 156, 2001-2012. doi: 10. 1097/j.pain.0000000000000260

Lambert, D. M., Vandevoorde, S., Jonsson, K. O., and Fowler, C. J. (2002). The palmitoylethanolamide family: a new class of anti-inflammatory agents? Curr. Med. Chem. 2002, 663-674. doi: 10.2174/0929867023370707

Laprairie, R. B., Bagher, A. M., Kelly, M. E., and Denovan-Wright, E. M. (2015). Cannabidiol is a negative allosteric modulator of the cannabinoid $\mathrm{CB}_{1}$ receptor. Br. J. Pharmacol. 172, 4790-4805. doi: 10.1111/bph.13250

Liang, Y. C., Huang, C. C., and Hsu, K. S. (2007). The synthetic cannabinoids attenuate allodynia and hyperalgesia in a rat model of trigeminal neuropathic pain. Neuropharmacology 53, 169-177. doi: 10.1016/j.neuropharm.2007. 04.019

Lichtman, A. H., Leung, D., Shelton, C. C., Saghatelian, A., Hardouin, C., Boger, D.-L., et al. (2004). Reversible inhibitors of fatty acid amide hydrolase that promote analgesia: evidence for an unprecedented combination of potency and selectivity. J. Pharmacol. Exp. Ther. 311, 441-448. doi: 10.1124/jpet.104. 069401

Lim, G., Sung, B., Ji, R. R., and Mao, J. (2003). Upregulation of spinal cannabinoid1-receptors following nerve injury enhances the effects of Win 55,212-2 on neuropathic pain behaviors in rats. Pain 105, 275-283. doi: 10.1016/S03043959(03)00242-2

Lomazzo, E., Bindila, L., Remmers, F., Lerner, R., Schwitter, C., Hoheisel, U., et al. (2015). Therapeutic potential of inhibitors of endocannabinoid degradation for the treatment of stress-related hyperalgesia in an animal model of chronic pain. Neuropsychopharmacology 40, 488-501. doi: 10.1038/npp.2014.198

Long, J. Z., Li, W., Booker, L., Burston, J. J., Kinsey, S. G., Schlosburg, J. E., et al. (2009). Selective blockade of 2-arachidonoylglycerol hydrolysis produces cannabinoid behavioral effects. Nat. Chem. Biol. 5, 37-44. doi: 10.1038/ nchembio. 129

Lowin, T., and Straub, R. H. (2015). Cannabinoid-based drugs targeting $\mathrm{CB}_{1}$ and TRPV1, the sympathetic nervous system, and arthritis. Arthritis Res. Ther. 17:226. doi: 10.1186/s13075-015-0743-x

Lucas, P. (2017). Rationale for cannabis-based interventions in the opioid overdose crisis. Harm Reduct. J. 14:58. doi: 10.1186/s12954-017-0183-9

Lucas, P., and Walsh, Z. (2017). Medical cannabis access, use, and substitution for prescription opioids and other substances: a survey of authorized medical cannabis patients. Int. J. Drug Policy 42, 30-35. doi: 10.1016/j.drugpo.2017. 01.011
Lynch, M. E., and Campbell, F. (2011). Cannabinoids for treatment of chronic noncancer pain; a systematic review of randomized trials. Br. J. Clin. Pharmacol. 72, 735-744. doi: 10.1111/j.1365-2125.2011.03970.x

Lynch, M. E., and Ware, M. A. (2015). Cannabinoids for the treatment of chronic non-cancer pain: an updated systematic review of randomized controlled trials. J. Neuroimmune Pharmacol. 10, 293-301. doi: 10.1007/s11481-015-9600-6

Maccarrone, M., Bab, I., Bíró, T., Cabral, G. A., Dey, S. K., Di Marzo, V., et al. (2015). Endocannabinoid signaling at the periphery: 50 years after THC. Trends Pharmacol. Sci. 36, 277-296. doi: 10.1016/j.tips.2015.02.008

Maida, V., Ennis, M., Irani, S., Corbo, M., and Dolzhykov, M. (2008). Adjunctive nabilone in cancer pain and symptom management: a prospective observational study using propensity scoring. J. Support. Oncol. 6, 119-124.

Maione, S., De Petrocellis, L., de Novellis, V., Moriello, A. S., Petrosino, S., Palazzo, E., et al. (2007). Analgesic actions of N-arachidonoyl-serotonin, a fatty acid amide hydrolase inhibitor with antagonistic activity at vanilloid TRPV1 receptors. Br. J. Pharmacol. 150, 766-781. doi: 10.1038/sj.bjp.0707145

Malek, N., and Starowicz, K. (2016). Dual-acting compounds targeting endocannabinoid and endovanilloid systems-a novel treatment option for chronic pain management. Front. Pharmacol. 7:257. doi: 10.3389/fphar.2016. 00257

Martin, B. R., Compton, D. R., Thomas, B. F., Prescott, W. R., Little, P. J., Razdan, R. K., et al. (1991). Behavioral, biochemical, and molecular modeling evaluations of cannabinoid analogs. Pharmacol. Biochem. Behav. 40, 471-478. doi: 10.1016/0091-3057(91)90349-7

Mattick, R. P. (2016). "The health and social effects of nonmedical cannabis use," in Wayne Hall, eds M. Renström and V. Poznyak (Geneva: World Health Organization).

Meng, H., Johnston, B., Englesakis, M., Moulin, D. E., and Bhatia, A. (2017). Selective cannabinoids for chronic neuropathic pain: a systematic review and meta-analysis. Anesth. Analg. 125, 1638-1652. doi: 10.1213/ANE. 0000000000002110

Meng, I. D., Manning, B. H., Martin, W. J., and Fields, H. L. (1998). An analgesia circuit activated by cannabinoids. Nature 395, 381-383. doi: 10.1038/26481

Mitrirattanakul, S., Ramakul, N., Guerrero, A. V., Matsuka, Y., Ono, T., Iwase, H., et al. (2006). Site-specific increases in peripheral cannabinoid receptors and their endogenous ligands in a model of neuropathic pain. Pain 126, 102-114. doi: 10.1016/j.pain.2006.06.016

Moore, N. (2016). Lessons from the fatal French study BIA-10-2474. BMJ 353:i2727. doi: 10.1136/bmj.i2727

Morales, P., Hurst, D. P., and Reggio, P. H. (2017). Molecular targets of the phytocannabinoids-a complex picture. Prog. Chem. Org. Nat. Prod. 103, 103131. doi: 10.1007/978-3-319-45541-9_4

Morera, E., Di Marzo, V., Monti, L., Allarà, M., Schiano Moriello, A., Nalli, M., et al. (2016). Arylboronic acids as dual-action FAAH and TRPV1 ligands. Bioorg. Med. Chem. Lett. 26, 1401-1405. doi: 10.1016/j.bmcl.2016.01.071

Moulin, D., Boulanger, A., Clark, A. J., Clarke, H., Dao, T., Finley, G. A., et al. (2014). Pharmacological management of chronic neuropathic pain: revised consensus statement from the Canadian Pain Society. Pain Res. Manag. 19, 328-335. doi: 10.1155/2014/754693

Mücke, M., Phillips, T., Radbruch, L., Petzke, F., and Häuser, W. (2018). Cannabisbased medicines for chronic neuropathic pain in adults. Cochrane Database Syst. Rev. 3:CD012182. doi: 10.1002/14651858.CD012182

NASEM (2017). National Academies of Sciences, Engineering, and Medicine; Health and Medicine Division; Board on Population Health and Public Health Practice; Committee on the Health Effects of Marijuana: An Evidence Review and Research Agenda. The Health Effects of Cannabis and Cannabinoids: The Current State of Evidence and Recommendations for Research. Washington, DC: National Academies Press.

Neugebauer, V. (2015). Amygdala pain mechanisms. Handb. Exp. Pharmacol. 227, 261-284. doi: 10.1007/978-3-662-46450-2_13

Nielsen, S., Sabioni, P., Trigo, J. M., Ware, M. A., Betz-Stablein, B. D., Murnion, B., et al. (2017). Opioid-sparing effect of cannabinoids: a systematic review and meta-analysis. Neuropsychopharmacology 42, 1752-1765. doi: 10.1038/npp. 2017.51

Niu, J., Huang, D., Zhou, R., Yue, M., Xu, T., Yang, J., et al. (2017). Activation of dorsal horn cannabinoid $\mathrm{CB}_{2}$ receptor suppresses the expression of $\mathrm{P} 2 \mathrm{Y}(12)$ and P2Y(13) receptors in neuropathic pain rats. J. Neuroinflammation 14:185. doi: 10.1186/s12974-017-0960-0 
Nosyk, B., and Wood, E. (2012). Evidence-based drug policy: it starts with good evidence and ends with policy reform. Int. J. Drug Policy 23, 423-425. doi: 10.1016/j.drugpo.2012.10.005

Noyes, R. Jr., Brunk, S. F., Avery, D. A., and Canter, A. C. (1975a). The analgesic properties of delta-9-tetrahydrocannabinol and codeine. Clin. Pharmacol. Ther. $18,84-89$.

Noyes, R. Jr., Brunk, S. F., Baram, D. A., and Canter, A. (1975b). Analgesic effect of delta-9-tetrahydrocannabinol. J. Clin. Pharmacol. 15, 139-143.

Ohlsson, A., Lindgren, J. E., Wahlen, A., Agurell, S., Hollister, L. E., and Gillespie, H. K. (1980). Plasma delta-9 tetrahydrocannabinol concentrations and clinical effects after oral and intravenous administration and smoking. Clin. Pharmacol. Ther. 28, 409-416. doi: 10.1038/clpt.1980.181

Olesen, A. E., Andresen, T., Staahl, C., and Drewes, A. M. (2012). Human experimental pain models for assessing the therapeutic efficacy of analgesic drugs. Pharmacol. Rev. 64, 722-779. doi: 10.1124/pr.111.005447

Ostenfeld, T., Price, J., Albanese, M., Bullman, J., Guillard, F., and Meyer, I. (2011). A randomized, controlled study to investigate the analgesic efficacy of single doses of the cannabinoid receptor-2 agonist GW842166, ibuprofen or placebo in patients with acute pain following third molar tooth extraction. Clin. J. Pain 27, 668-676. doi: 10.1097/AJP.0b013e318219799a

O'Sullivan, S. E. (2016). An update on PPAR activation by cannabinoids. Br. J. Pharmacol. 173, 1899-1910. doi: 10.1111/bph.13497

Oz, M., Al Kury, L., Keun-Hang, S. Y., Mahgoub, M., and Galadari, S. (2014). Cellular approaches to the interaction between cannabinoid receptor ligands and nicotinic acetylcholine receptors. Eur. J. Pharmacol. 731, 100-105. doi: 10.1016/j.ejphar.2014.03.010

Pacher, P., Bátkai, S., and Kunos, G. (2006). The endocannabinoid system as an emerging target of pharmacotherapy. Pharmacol. Rev. 58, 389-462. doi: 10. 1124/pr.58.3.2

Pascual, D., Goicoechea, C., Suardíaz, M., and Martín, M. I. (2005). A cannabinoid agonist, WIN 55,212-2, reduces neuropathic nociception induced by paclitaxel in rats. Pain 118, 23-34. doi: 10.1016/j.pain.2005.07.008

Pawsey, S., Wood, M., Browne, H., Donaldson, K., Christie, M., and Warrington, S. (2016). Safety, tolerability and pharmacokinetics of FAAH inhibitor V158866: a double-blind, randomised, placebo-controlled phase I study in healthy volunteers. Drugs R D 16, 181-191. doi: 10.1007/s40268-016-0127-y

PDQ Integrative Alternative and Complementary Therapies Editorial Board (2018). Cannabis and Cannabinoids $\left(P D Q^{\circledR}\right)$ : Health Professional Version," in: PDQ Cancer Information Summaries [Internet]. Bethesda, MD: National Cancer Institute.

Pereira, A., Chappell, A., Dethy, J., Hoeck, H., Arendt-Nielsen, L., Verfaille, S., et al. (2013). A proof-of-concept (POC) study including experimental pain models (EPMs) to assess the effects of a $\mathrm{CB}_{2}$ agonist (LY2828360) in the treatment of patients with osteoarthritic (OA) knee pain. Clin. Pharmacol. Ther. 93, S56-S57.

Pernía-Andrade, A. J., Kato, A., Witschi, R., Nyilas, R., Katona, I., Freund, T. F., et al. (2009). Spinal endocannabinoids and $\mathrm{CB}_{1}$ receptors mediate C-fiberinduced heterosynaptic pain sensitization. Science 325, 760-764. doi: 10.1126/ science. 1171870

Pertwee, R. G. (2008). The diverse $\mathrm{CB}_{1}$ and $\mathrm{CB}_{2}$ receptor pharmacology of three plant cannabinoids: $\Delta$ 9-tetrahydrocannabinol, cannabidiol and $\Delta 9$ tetrahydrocannabivarin. Br. J. Pharmacol. 153, 199-215. doi: 10.1038/sj.bjp. 0707442

Pertwee, R. G., Howlett, A. C., Abood, M. E., Alexander, S. P., Di Marzo, V., Elphick, M. R., et al. (2010). International union of basic and clinical pharmacology. LXXIX. Cannabinoid receptors and their ligands: beyond CB1 and CB2. Pharmacol. Rev. 62, 588-631. doi: 10.1124/pr.110.003004

Petrosino, S., Palazzo, E., de Novellis, V., Bisogno, T., Rossi, F., Maione, S., et al. (2007). Changes in spinal and supraspinal endocannabinoid levels in neuropathic rats. Neuropharmacology 52, 415-422. doi: 10.1016/j.neuropharm. 2006.08.011

Piomelli, D. (2014). More surprises lying ahead. The endocannabinoids keep us guessing. Neuropharmacology 76, 228-234. doi: 10.1016/j.neuropharm.2013.07. 026

Piomelli, D., Cooper, Z., Abrams, D., Grant, I., and Patel, S. (2017). A guide to the national academy of science report on cannabis: an exclusive discussion with panel members. Cannabis Cannabinoid Res. 2, 155-159. doi: 10.1089/can.2017. 29009.dpi
Piomelli, D., and Sasso, O. (2014). Peripheral gating of pain signals by endogenous lipid mediators. Nat. Neurosci. 17, 164-174. doi: 10.1038/nn.3612

Piper, B. J., DeKeuster, R. M., Beals, M. L., Cobb, C. M., Burchman, C. A., Perkinson, L., et al. (2017). Substitution of medical cannabis for pharmaceutical agents for pain, anxiety, and sleep. J. Psychopharmacol. 31, 569-575. doi: 10. $1177 / 0269881117699616$

Portenoy, R. K., Ganae-Motan, E. D., Allende, S., Yanagihara, R., Shaiova, L., Weinstein, S., et al. (2012). Nabiximols for opioid-treated cancer patients with poorly-controlled chronic pain: a randomized, placebo-controlled, graded-dose trial. J. Pain 13, 438-449. doi: 10.1016/j.jpain.2012.01.003

Powell, D., Pacula, R. L., and Jacobson, M. (2018). Do medical marijuana laws reduce addictions and deaths related to pain killers? J. Health Econ. 58, 29-42. doi: 10.1016/j.jhealeco.2017.12.007

Price, M. R., Baillie, G. L., Thomas, A., Stevenson, L. A., Easson, M., and Goodwin, R. (2005). Allosteric modulation of the cannabinoid $\mathrm{CB}_{1}$ receptor. Mol. Pharmacol. 68, 1484-1495. doi: 10.1124/mol.105.016162

Quartilho, A., Mata, H. P., Ibrahim, M. M., Vanderah, T. W., Porreca, F., and Makriyannis, A. (2003). Inhibition of inflammatory hyperalgesia by activation of peripheral $\mathrm{CB}_{2}$ cannabinoid receptors. Anesthesiology 99, 955-960. doi: 10 . 1097/00000542-200310000-00031

Racz, I., Nadal, X., Alferink, J., Baños, J. E., Rehnelt, J., Martí, M., et al. (2008). Interferon-gamma is a critical modulator of $\mathrm{CB}_{2}$ cannabinoid receptor signaling during neuropathic pain. J. Neurosci. 28, 12136-12145. doi: 10.1523/ JNEUROSCI.3402-08.2008

Rahn, E. J., and Hohmann, A. G. (2009). Cannabinoids as pharmacotherapies for neuropathic pain: from the bench to the bedside. Neurotherapeutics 6, 713-737. doi: 10.1016/j.nurt.2009.08.002

Rahn, E. J., Makriyannis, A., and Hohmann, A. G. (2007). Activation of cannabinoid $\mathrm{CB}_{1}$ and $\mathrm{CB}_{2}$ receptors suppresses neuropathic nociception evoked by the chemotherapeutic agent vincristine in rats. Br. J. Pharmacol. 152, 765-777. doi: 10.1038/sj.bjp.0707333

Reddy, A. S., and Zhang, S. (2013). Polypharmacology: drug discovery for the future. Expert Rev. Clin. Pharmacol. 6, 41-47. doi: 10.1586/ecp.12.74

Roche, M., and Finn, D. P. (2010). Brain $\mathrm{CB}_{2}$ receptors: implications for neuropsychiatric disorders. Pharmaceuticals 3, 2517-2553. doi: 10.3390/ ph3082517

Rockwell, C. E., and Kaminski, N. E. (2004). A cyclooxygenase metabolite of anandamide causes inhibition of interleukin-2 secretion in murine splenocytes. J. Pharmacol. Exp. Ther. 311, 683-690. doi: 10.1124/jpet.104.065524

Rog, D. J., Nurmikkom, T. J., and Young, C. A. (2007). Oromucosal delta9-tetrahydrocannabinol/cannabidiol for neuropathic pain associated with multiple sclerosis: an uncontrolled, open-label, 2-year extension trial. Clin. Ther. 29, 2068-2079. doi: 10.1016/j.clinthera.2007.09.013

Romano, M. R., and Lograno, M. D. (2012). Involvement of the peroxisome proliferator-activated receptor (PPAR) alpha in vascular response of endocannabinoids in the bovine ophthalmic artery. Eur. J. Pharmacol. 683, 197-203. doi: 10.1016/j.ejphar.2012.02.049

Romero-Sandoval, E. A., Kolano, A. L., and Alvarado-Vázquez, P. A. (2017). Cannabis and cannabinoids for chronic pain. Curr. Rheumatol. Rep. 19:67. doi: 10.1007/s11926-017-0693-1

Rong, C., Carmona, N. E., Lee, Y. L., Ragguett, R. M., Pan, Z., Rosenblat, J. D., et al. (2018). Drug-drug interactions as a result of co-administering $\Delta$ (9)-THC and CBD with other psychotropic agents. Expert Opin. Drug Saf. 17, 51-54. doi: 10.1080/14740338.2017.1397128

Ross, R. A. (2003). Anandamide and vanilloid TRPV1 receptors. Br. J. Pharmacol. 40, 790-801. doi: 10.1038/sj.bjp.0705467

Russo, E., and Guy, G. W. (2006). A tale of two cannabinoids: the therapeutic rationale for combining tetrahydrocannabinol and cannabidiol. Med. Hypotheses 66, 234-246. doi: 10.1016/j.mehy.2005.08.026

Russo, E. B. (2011). Taming THC: potential cannabis synergy and phytocannabinoid-terpenoid entourage effects. Br. J. Pharmacol. 163, 1344-1364. doi: 10.1111/j.1476-5381.2011.01238.x

Russo, E. B., Burnett, A., Hall, B., and Parker, K. K. (2005). Agonistic properties of cannabidiol at 5-HT1a receptors. Neurochem. Res. 30, 1037-1043. doi: 10.1007/ s11064-005-6978-1

Ryberg, E., Larsson, N., Sjögren, S., Hjorth, S., Hermansson, N. O., Leonova, J., et al. (2007). The orphan receptor GPR55 is a novel cannabinoid receptor. Br. J. Pharmacol. 152, 1092-1101. doi: 10.1038/sj.bjp.0707460 
Sagar, D. R., Kendall, D. A., and Chapman, V. (2008). Inhibition of fatty acid amide hydrolase produces PPAR-alpha-mediated analgesia in a rat model of inflammatory pain. Br. J. Pharmacol. 155, 1297-1306. doi: 10.1038/bjp.2008.335

Sasso, O., Migliore, M., Habrant, D., Armirotti, A., Albani, C., and Summa, M. (2015). Multitarget fatty acid amide hydrolase/cyclooxygenase blockade suppresses intestinal inflammation and protects against nonsteroidal antiinflammatory drug-dependent gastrointestinal damage. FASEB J. 29, 26162627. doi: 10.1096/fj.15-270637

Scavone, J. L., Sterling, R. C., and Van Bockstaele, E. J. (2013). Cannabinoid and opioid interactions: implications for opiate dependence and withdrawal. Neuroscience 248, 637-654. doi: 10.1016/j.neuroscience.2013.04.034

Schlosburg, J. E., Carlson, B. L., Ramesh, D., Abdullah, R. A., Long, J. Z., Cravatt, B. F., et al. (2009). Lichtman AH. Inhibitors of endocannabinoid-metabolizing enzymes reduce precipitated withdrawal responses in THC-dependent mice. AAPS J. 11, 342-352. doi: 10.1208/s12248-009-9110-7

Schuelert, N., Johnson, M. P., Oskins, J. L., Jassal, K., Chambers, M. G., and McDougall, J. J. (2011). Local application of the endocannabinoid hydrolysis inhibitor URB597 reduces nociception in spontaneous and chemically induced models of osteoarthritis. Pain 152, 975-981. doi: 10.1016/j.pain.2010.11.025

Serpell, M. G., Notcutt, W., and Collin, C. (2013). Sativex long-term use: an openlabel trial in patients with spasticity due to multiple sclerosis. J. Neurol. 260, 285-295. doi: 10.1007/s00415-012-6634-z

Shi, B., Yang, R., Wang, X., Liu, H., Zou, L., and Hu, X. (2012). Inhibition of 5$\mathrm{HT}(3)$ receptors-activated currents by cannabinoids in rat trigeminal ganglion neurons. J. Huazhong Univ. Sci. Technolog. Med. Sci. 32, 265-271. doi: 10.1007/ s11596-012-0047-1

Sigel, E., Baur, R., Rácz, I., Marazzi, J., Smart, T. G., Zimmer, A., et al. (2011). The major central endocannabinoid directly acts at GABA(A) receptors. Proc. Natl. Acad. Sci. U.S.A. 108, 18150-18155. doi: 10.1073/pnas.1113444108

Slivicki, R. A., Xu, Z., Kulkarni, P. M., Pertwee, R. G., Mackie, K., Thakur, G. A., et al. (2017). Positive allosteric modulation of cannabinoid receptor type 1 suppresses pathological pain without producing tolerance or dependence. Biol. Psychiatry doi: 10.1016/j.biopsych.2017.06.032 [Epub ahead of print].

Small-Howard, A. L., Shimoda, L. M., Adra, C. N., and Turner, H. (2005). Anti-inflammatory potential of $\mathrm{CB}_{1}$-mediated cAMP elevation in mast cells. Biochem. J. 388, 465-473. doi: 10.1042/BJ20041682

Smith, N. (2015). Transdermal Cannabinoid Patch. U.S. Patent No 20,150,297,556. Washington, DC: U.S.Patent and Trademark Office.

Srebro, D., Vučković, S., Milovanović, A., Košutić, J., Vujović, K. S., and Prostran, M. (2016). Magnesium in pain research: state of the art. Curr. Med. Chem. [Epub ahead of print].

Starowicz, K., and Finn, D. P. (2017). Cannabinoids and pain: sites and mechanisms of action. Adv. Pharmacol. 80, 437-475. doi: 10.1016/bs.apha.2017. 05.003

Starowicz, K., Makuch, W., Osikowicz, M., Piscitelli, F., Petrosino, S., and Di Marzo, V. (2012). Spinal anandamide produces analgesia in neuropathic rats: possible $\mathrm{CB}_{1}$ - and TRPV1-mediated mechanisms. Neuropharmacology 62, 1746-1755. doi: 10.1016/j.neuropharm.2011.11.021

Starowicz, K., and Przewlocka, B. (2012). Modulation of neuropathic-pain-related behaviour by the spinal endocannabinoid/endovanilloid system. Philos. Trans. R. Soc. Lond. B Biol. Sci. 367, 3286-3299. doi: 10.1098/rstb.2011.0392

Staton, P. C., Hatcher, J. P., Walker, D. J., Morrison, A. D., Shapland, E. M., Hughes, J. P., et al. (2008). The putative cannabinoid receptor GPR55 plays a role in mechanical hyperalgesia associated with inflammatory and neuropathic pain. Pain 139, 225-236. doi: 10.1016/j.pain.2008.04.006

Sumariwalla, P. F., Gallily, R., Tchilibon, S., Fride, E., Mechoulam, R., and Feldmann, M. (2004). A novel synthetic, nonpsychoactive cannabinoid acid (HU-320) with antiinflammatory properties in murine collagen-induced arthritis. Arthritis Rheum. 50, 985-998. doi: 10.1002/art.20050

Sun, Y., Alexander, S. P., Garle, M. J., Gibson, C. L., Hewitt, K., Murphy, S. P., et al. (2007). Cannabinoid activation of PPAR alpha; a novel neuroprotective mechanism. Br. J. Pharmacol. 152, 734-743. doi: 10.1038/sj.bjp.0707478

Thomas, A., Baillie, G. L., Phillips, A. M., Razdan, R. K., Ross, R. A., and Pertwee, R. G. (2007). Cannabidiol displays unexpectedly high potency as an antagonist of $\mathrm{CB}_{1}$ and $\mathrm{CB}_{2}$ receptor agonists in vitro. Br. J. Pharmacol. 150, 613-623. doi: 10.1038/sj.bjp.0707133

Tomić, M., Pecikoza, U., Micov, A., Vučković, S., and Stepanović-Petrović, R. (2018). Antiepileptic drugs as analgesics/adjuvants in inflammatory pain: current preclinical evidence. Pharmacol. Ther. doi: 10.1016/j.pharmthera.2018. 06.002 [Epub ahead of print].

Toth, C. C., Jedrzejewski, N. M., Ellis, C. L., and Frey, W. H. (2010). Cannabinoidmediated modulation of neuropathic pain and microglial accumulation in a model of murine type I diabetic peripheral neuropathic pain. Mol. Pain 6:16. doi: 10.1186/1744-8069-6-16

Turcotte, C., Blanchet, M. R., Laviolette, M., and Flamand, N. (2016). The $\mathrm{CB}_{2}$ receptor and its role as a regulator of inflammation. Cell. Mol. Life Sci. 73, 4449-4470. doi: 10.1007/s00018-016-2300-4

Vaughan, C. W., and Christie, M. J. (2005). Retrograde signalling by endocannabinoids. Handb. Exp. Pharmacol. 168, 367-383. doi: 10.1007/3-54026573-2_12

Vincent, L., Vang, D., Nguyen, J., Benson, B., Lei, J., and Gupta, K. (2016). Cannabinoid receptor-specific mechanisms to alleviate pain in sickle cell anemia via inhibition of mast cell activation and neurogenic inflammation. Haematologica 101, 566-577. doi: 10.3324/haematol.2015.136523

Volkow, N. D., Compton, W. M., and Weiss, S. R. (2014). Adverse health effects of marijuana use. N. Engl. J. Med. 371:879. doi: 10.1056/NEJMc1407928

Vučković, S., Prostran, M., Ivanović, M., Dosen-Mićović, L. J., Todorović, Z., Nesić, Z., et al. (2009). Fentanyl analogs: structure-activity-relationship study. Curr. Med. Chem. 16, 2468-2474. doi: 10.2174/092986709788682074

Vučković, S., Savić Vujović, K., Srebro, D., Medić, B., and Ilić-Mostić, T. (2016). Prevention of renal complications induced by non-steroidal antiinflammatory drugs. Curr. Med. Chem. 23, 1953-1964. doi: 10.2174/ 0929867323666160210125920

Vučković, S., Tomic, M., Stepanovic-Petrovic, R., Ugresic, N., Prostran, M., and Boskovic, B. (2006). Peripheral antinociception by carbamazepine in an inflammatory mechanical hyperalgesia model in the rat: a new target for carbamazepine? J. Pharmacol. Sci. 100, 310-314. doi: 10.1254/jphs.SCE05003X

Vučković, S. M., Tomić, M. A., Stepanović-Petrović, R. M., Ugresić, N., Prostran, M. S., and Bosković, B. (2006). The effects of alpha2-adrenoceptor agents on anti-hyperalgesic effects of carbamazepine and oxcarbazepine in a rat model of inflammatory pain. Pain 125, 10-19. doi: 10.1016/j.pain.2006.04.023

Vučković, S. M., Savić Vujović, K. R., Srebro, D. P., Medić, B. M., Stojanović, R.-M., Vučetić, C. S., et al. (2015). The antinociceptive efficacy of morphineketamine-magnesium combination is influenced by the order of medication administration. Eur. Rev. Med. Pharmacol. Sci. 19, 3286-3294.

Wade, D. T., Makela, P. M., House, H., Bateman, C., and Robson, P. (2006). Long-term use of a cannabis-based medicine in the treatment of spasticity and other symptoms in multiple sclerosis. Mult. Scler. 12, 639-645. doi: 10.1177/ 1352458505070618

Wade, D. T., Robson, P., House, H., Makela, P., and Aram, J. (2003). A preliminary controlled study to determine whether whole-plant cannabis extracts can improve intractable neurogenic symptoms. Clin. Rehabil. 17, 21-29. doi: 10. 1191/0269215503cr581oa

Walker, J. M., Hohmann, A. G., Martin, W. J., Strangman, N. M., Huang, S. M., and Tsou, K. (1999). The neurobiology of cannabinoid analgesia. Life Sci. 65, 665-673. doi: 10.1016/S0024-3205(99)00289-1

Wall, M. E., Sadler, B. M., Brine, D., Taylor, H., and Perez-Reyes, M. (1983). Metabolism, disposition, and kinetics of delta-9-tetrahydrocannabinol in men and women. Clin. Pharmacol. Ther. 34, 352-363. doi: 10.1038/clpt.1983.179

Wallace, M. S., Marcotte, T. D., Umlauf, A., Gouaux, B., and Atkinson, J. H. (2015). Efficacy of inhaled cannabis on painful diabetic neuropathy. J. Pain 16, 616-627. doi: 10.1016/j.jpain.2015.03.008

Wang, T., Collet, J. P., Shapiro, S., and Ware, M. A. (2008). Adverse effects of medical cannabinoids: a systematic review. CMAJ 178, 1669-1678. doi: 10.1503/ cmaj.071178

Ward, S. J., McAllister, S. D., Kawamura, R., Murase, R., Neelakantan, H., and Walker, E. A. (2014). Cannabidiol inhibits paclitaxel-induced neuropathic pain through $5-\mathrm{HT}(1 \mathrm{~A})$ receptors without diminishing nervous system function or chemotherapy efficacy. Br. J. Pharmacol. 171, 636-645. doi: 10.1111/bph. 12439

Ware, M. A., Wang, T., Shapiro, S., Collet, J. P., and Compass study team (2015). Cannabis for the management of pain: assessment of safety study (COMPASS). J. Pain 16, 1233-1242. doi: 10.1016/j.jpain.2015.07.014

Whiting, P. F., Wolff, R. F., Deshpande, S., Di Nisio, M., Duffy, S., Hernandez, A. V., et al. (2015). Cannabinoids for medical use: a systematic review and meta-analysis. JAMA 313, 2456-2473. doi: 10.1001/jama.2015.6358 
Wilkerson, J. L., Gentry, K. R., Dengler, E. C., Wallace, J. A., Kerwin, A. A., Armijo, L. M., et al. (2012). Intrathecal cannabilactone CB 2R agonist, AM1710, controls pathological pain and restores basal cytokine levels. Pain 153, 1091-1106. doi: 10.1016/j.pain.2012.02.015

Wilsey, B., Marcotte, T., Deutsch, R., Gouaux, B., Sakai, S., and Donaghe, H. (2013). Low-dose vaporized cannabis significantly improves neuropathic pain. J. Pain 14, 136-148. doi: 10.1016/j.jpain.2012.10.009

Wilsey, B. L., Deutsch, R., Samara, E., Marcotte, T. D., Barnes, A. J., Huestis, M. A., et al. (2016). A preliminary evaluation of the relationship of cannabinoid blood concentrations with the analgesic response to vaporized cannabis. J. Pain Res. 9, 587-598. doi: 10.2147/JPR.S113138

Woodhams, S. G., Chapman, V., Finn, D. P., Hohmann, A. G., and Neugebauer, V. (2017). The cannabinoid system and pain. Neuropharmacology 124, 105-120. doi: 10.1016/j.neuropharm.2017.06.015

Xiong, W., Cheng, K., Cui, T., Godlewski, G., Rice, K. C., and Xu, Y. (2011). Cannabinoid potentiation of glycine receptors contributes to cannabis-induced analgesia. Nat. Chem. Biol. 7, 296-303. doi: 10.1038/nchembio.552

Xiong, W., Cui, T., Cheng, K., Yang, F., Chen, S. R., Willenbring, D., et al. (2012). Cannabinoids suppress inflammatory and neuropathic pain by targeting $\alpha 3$ glycine receptors. J. Exp. Med. 209, 1121-1134. doi: 10.1084/jem.20120242

Yaksh, T. L., Woller, S. A., Ramachandran, R., and Sorkin, L. S. (2015). The search for novel analgesics: targets and mechanisms. F1000Prime Rep. 7:56. doi: 10.12703/P7-56

Yamamoto, W., Mikami, T., and Iwamura, H. (2008). Involvement of central cannabinoid $\mathrm{CB}_{2}$ receptor in reducing mechanical allodynia in a mouse model of neuropathic pain. Eur. J. Pharmacol. 583, 56-61. doi: 10.1016/j.ejphar.2008. 01.010

Yu, X. H., Cao, C. Q., Martino, G., Puma, C., Morinville, A., St-Onge, S., et al. (2010). A peripherally restricted cannabinoid receptor agonist produces robust anti-nociceptive effects in rodent models of inflammatory and neuropathic pain. Pain 151, 337-344. doi: 10.1016/j.pain.2010.07.019

Zádor, F., and Wollemann, M. (2015). Receptome: interactions between three pain-related receptors or the "Triumvirate" of cannabinoid, opioid and TRPV1 receptors. Pharmacol. Res. 102, 254-263. doi: 10.1016/j.phrs.2015. 10.015

Zajicek, J. P., Sanders, H. P., Wright, D. E., Vickery, P. J., Ingram, W. M., Reilly, S. M., et al. (2005). Cannabinoids in multiple sclerosis (CAMS) study: safety and efficacy data for 12 months follow up. J. Neurol. Neurosurg. Psychiatry 76, 1664-1669. doi: 10.1136/jnnp.2005.070136

Zhang, J., Hoffert, C., Vu, H. K., Groblewski, T., Ahmad, S., and O’Donnell, D. (2003). Induction of $\mathrm{CB}_{2}$ receptor expression in the rat spinal cord of neuropathic but not inflammatory chronic pain models. Eur. J. Neurosci. 17, 2750-2754. doi: 10.1046/j.1460-9568.2003.02704.x

Zuurman, L., Ippel, A. E., Moin, E., and van Gerven, J. M. (2009). Biomarkers for the effects of cannabis and THC in healthy volunteers. Br. J. Clin. Pharmacol. 67, 5-21. doi: 10.1111/j.1365-2125.2008.03329.x

Conflict of Interest Statement: The authors declare that the research was conducted in the absence of any commercial or financial relationships that could be construed as a potential conflict of interest.

Copyright (c) 2018 Vučković, Srebro, Vujović, Vučetić and Prostran. This is an openaccess article distributed under the terms of the Creative Commons Attribution License (CC BY). The use, distribution or reproduction in other forums is permitted, provided the original author(s) and the copyright owner(s) are credited and that the original publication in this journal is cited, in accordance with accepted academic practice. No use, distribution or reproduction is permitted which does not comply with these terms. 